\title{
SOBRE LA CORRUPCIÓN: UN ANÁLISIS MULTIDISCIPLINAR
}

\author{
Jaime Rodríguez-Arana1
}

\section{A. APROXIMACIÓN GENERAL}

La corrupción, mal que nos pese, es una realidad. Una amarga realidad que crece y crece sin césar sin que aparentemente seamos capaces de expulsarla de las prácticas políticas y administrativas. Se publican leyes y leyes, se promulgan códigos y códigos, pero ahí está ante nuestra mirada uno de los principales flagelos que impide el primado de los derechos fundamentales de la persona.

Pues bien, uno de los aspectos que se debe combatir desde la Ética pública es la corrupción. Es evidente que la corrupción, en cuanto que utilización de potestades públicas para la satisfacción de intereses puramente personales o extrapúblicos, es un fenómeno atemporal y universal pues en todos los colectivos han existido personas que no han seguido las reglas del juego. Sin embargo, debe subrayarse que aunque en este tiempo aparezcan recurrentemente en los medios de comunicación noticias referidas a presuntas corrupciones, la realidad es que por más lamentable que sea, la corrupción campa a sus anchas ante la impotencia de las distintas técnicas que se han alumbrado en la lucha contra esta lacra social que tanto daño hace al sistema político².

1 Catedrático de Derecho Administrativo y Director del Grupo de Investigación de Derecho Público Global de la Universidad de a Coruña.

\footnotetext{
${ }^{2}$ Vid., por ejemplo, N.H. LEFF, Economic development through bureaucratic corruption, The American behariourial scientist, vol. 8, 1964; R. BRAIBANTI, Reflections on bureaucratic corruption, Journal of the Royal Institute of Public Administration, vol. 42, 1962, JVAN KLAVERN, The concept of corruption, en REVISTA DO DIREITO UNISC, SANTA CRUZ DO SUL $N^{\circ} 41 \mid$ p. 110 - 168|NOV - DEZ 2013
} 
La corrupción, bien lo sabemos, supone un atentado grave a la misma esencia del servicio público en la medida que supone que el funcionario o político deliberadamente traiciona el sentido de la gestión de los intereses colectivos actuando en contra del bien común ${ }^{3}$, conculcando el interés general que debe servir objetivamente. En estos casos se produce, por tanto, una conversión del interés general en interés personal. Esa es su malicia y su peligro ${ }^{4}$.

En una sociedad como la occidental, en la que los intereses públicos son distintos, aunque no contrapuestos, a los intereses privados, la corrupción es la más grave conducta anti-ética. Y, si tenemos en cuenta que precisamente la sociedad occidental moderna se caracteriza por una excesiva valoración de lo "personal", por un desproporcionado apego a los bienes materiales y por una triste falta de sensibilidad, aunque mucho se hable de derechos humanos, frente a la dignidad del hombre, nos encontramos con un ambiente en el que difícilmente cuajan auténticas vocaciones para el servicio público. Es más, la actual crisis económica y financiera no es más, en este punto, que el trasunto de una visión demasiado economicista del servicio público. De ahí la importancia de los programas de Ética pública y la necesidad de potenciar ambientes de altura ética para el ejercicio de la función pública pues en, no pocas casos, la sociedad actual coloca en el candelero a personas que triunfan en la empresa privada a través de procedimientos que no suelen ser homologables en la Administración pública.

La corrupción en la función pública es una cuestión muy delicada. Conviene insistir en que la mayoría de los servidores públicos trabajan bien y son honestos. El problema es esa minoría, a veces puede mayoritaria en ambientes de corrupción institucionalizada, que existe en todos los países, de "manzanas

Political corruption, New York, 1970, pp 38-40, B.N. SANDS, Decentralizing and economy: the role of bureaucratic corruption in china's economic reforms, Public choice n ${ }^{\circ} 65,1990$, pp 85 y 55.

${ }^{3}$ Sobre la corrupción política, en general, Vid. F. LAPORTA, La corrupción política, en F. LAPORTA-S. ÁLVAREZ (Eds.), La corrupción política, Madrid, 1997, pp. 19 y ss.

${ }^{4}$ Vid. A.J. HEIDENHEIMER-M. JOHNSTOON-V.T. LECINE, Political corruption, New York, 1989, pp. 4 y ss.

REVISTA DO DIREITO UNISC, SANTA CRUZ DO SUL No $41 \mid$ p. 110 - 168| NOV - DEZ 2013 
podridas", puede contagiar al resto. La cuestión es reaccionar, desde el aparato público, y desde la dimensión personal, con contundencia porque, de lo contrario, se podría generar un ambiente en el que se pretenda imitar la conducta de quien utiliza la discrecionalidad administrativa en su beneficio propio. La lucha contra esta lacra social debe ser a través de las vías jurídicas y, a través, de planes periódicos de Ética pública en los que queden muy claro los fines del servicio público y la "anormalidad" del uso de los poderes públicos en exclusivo beneficio personal.

En los países del tercer mundo la lucha contra la corrupción es francamente difícil porque este fenómeno, lamentablemente, es normal en las relaciones sociales. En estos países, prácticamente no se distingue entre interés público e interés privado o personal, lo que se traduce en una cultura de corrupción que se hace permeable en todos los aspectos sociales. En este contexto, la impotencia de los funcionarios públicos para controlar las actividades inmorales, les lleva a elegir entre aplicar los criterios de la Ética pública y aislarse del sistema o hacer uso de las potestades públicas para satisfacer las exigencias de sus clientes y amigos y, por tanto, promover aún más el mal que están llamados a curar. En el caso de estos países, la corrupción debe desaparecer primero de las prácticas sociales a través de un proceso de sustitución de modelos que fomentan la inmoralidad por conductas a favor de la integridad, la honestidad y la eficacia ${ }^{5}$.

En este sentido, debemos recordar algunas de las características de los países donde la corrupción es la norma. Siguiendo al profesor CAIDEN, podemos resumir en diez las principales características de una situación de corrupción sistemática institucionalizada. Veamos.

a) La burocracia posee unos criterios éticos externos que se contradicen con la praxis administrativa interna.

\footnotetext{
${ }^{5}$ Cfr. J. JABBRA y N. JABBRA, loc. cit, pp. 673-691

REVISTA DO DIREITO UNISC, SANTA CRUZ DO SUL $\mathrm{N}^{\circ} 41 \mid$ p. $110-168 \mid$ NOV - DEZ 2013
} 
b) La praxis interna administrativa facilita la omisión de los criterios éticos que se predican hacia el exterior.

c) Los funcionarios que se distinguen por su honestidad e imparcialidad son una excepción y deben "renunciar" a los beneficios de una actuación corrupta generalizada.

d) Los funcionarios corruptos, que son mayoría, son protegidos $y$, cuando se les descubre, se les trata con indulgencia, mientras que los acusadores son víctimas de persecución.

e) Los funcionarios honestos encuentran dificultades ambientales para desarrollar su labor con profesionalidad.

f) La responsabilidad de estas situaciones se resuelve en la función de racionalización de las prácticas administrativas internas.

g) Los encargados de perseguir la corrupción raramente actúan $y$, cuando lo hacen, disculpan cualquier incidente como un hecho aislado.

h) Se produce la ausencia de la idea del servicio público. Los funcionarios contemplan su trabajo administrativo como oportunidad de explotarlo en beneficio propio.

i) La corrupción crece allí donde los ciudadanos no se identifican con los intereses generales y dónde las autoridades se distancian del pueblo. Entonces, se produce una suerte de falta de interés, caso del colectivismo reciente.

j) Ausencia de virtudes cívicas. En estos países es más importante la ganancia personal que colaborar en la gestión de los intereses colectivos. En general, se detecta una falta de ciudadanos con fuerza moral para sobreponerse a estas situaciones.

Tiempo atrás cayó en mis manos un libro de la colección Civitas escrito por el magistrado y funcionario excedente Alfonso SABÁN GODOY titulado "El marco jurídico de la corrupción" que lleva una presentación del profesor GARCÍA DE ENTERRRIA. En el trabajo de SABAN se plantean temas importantes 
como el de corrupción y legalidad, el substrato fáctico de la corrupción, los conflictos de interés o las técnicas jurídicas de control de la actividad pública en España.

SABAN señala que toda conducta corrupta es una conducta iconstitucional porque lesiona el derecho a contar con una Administración que sirva con objetividad los intereses generales ${ }^{6}$. Por ello, la desviación de intereses debe ir acompañada de sanciones normativas desde una perspectiva de interpretación finalista o teleológica del Ordenamiento ya que, dice SABAN, las normas son reglas de convivencia que se justifican porque pretenden alcanzar un fin. Es más, si bien la conducta pública ha de mantener la legalidad como término de referencia obligado, tal referencia debe entenderse en el sentido más avanzado del término, es decir, entendiendo la legalidad como un sistema racional en el que los elementos se relacionan por identidad de fines ${ }^{7}$. Por tanto, la corrupción, en cualquiera de sus formas, además de constituir un claro atentado a los más elementales principios de la Ética pública, puede ser merecedora de la sanción normativa en cuanto que desviación de intereses.

Desde el punto de vista fenomenológico, SABAN hace una precisión de indudable interés. El empleado público que cae en la corrupción normalmente ha seguido prácticas que se dan en el sector privado. Es el caso de la transmisión de información privilegiada o de la puesta en marcha de negocios paralelos. Esto quiere decir, entre otras cosas, que la corrupción en el ámbito público tiene mucho de ver con el ambiente de lealtad y competencia que se da en la empresa privada. Es decir, el índice de corrupción pienso que está en relación directa con la calidad de la vida social, con la temperatura de la exigencia ética general que se respira en la realidad cotidiana.

Quizás la lucha contra la corrupción sea una batalla lenta y difícil. Sin embargo, los Gobiernos deben articular las medidas necesarias para evitar la institucionalización de la corrupción porque una vez que la corrupción se extiende,

\footnotetext{
${ }^{6}$ Artículo 103 de la Constitución española de 1.978

${ }^{7}$ A. SABÁN, El marco jurídico de la corrupción, Madrid, 1991, pp. 17,18 y 19.
}

REVISTA DO DIREITO UNISC, SANTA CRUZ DO SUL No $41 \mid$ p. 110 - 168| NOV - DEZ 2013 
las posibilidades de éxito son muy pequeñas. En efecto, el profesor CAIDEN señala que deben existir manuales anti-corrupción con definiciones practicas por sectores de actividad administrativa, que faciliten una especial sensibilidad que haga posible revelar cualquier forma de corrupción.

La corrupción lesiona los valores éticos del servicio público en cuanto que supone la utilización de potestades públicas para el exclusivo provecho personal, familiar o de grupo del funcionario o gestor público. Equivale a la desnaturalización de la función constitucional de la Administración pública que consiste en servir con objetividad los intereses generales. Por eso, el Derecho es el instrumento adecuado para sancionar este tipo de conductas amén de que la conculcación de los más elementales valores éticos también suponga una pena quizás más dura socialmente.

A continuación estudiaremos brevemente el alcance del sistema penal, contencioso-administrativo y civil en la lucha contra la corrupción. La perspectiva penal quizás no sea el instrumento más idóneo para la lucha anti-corrupción pues como señala SABAN las conductas, a medida que suponen mayores consecuencias económicas, tienen menos encaje en los tipos ${ }^{8}$. Además, los elementos estructurales de la técnica penal, tipo y culpa, son de difícil subsunción en los supuestos de corrupción. Sobre todo, el elemento culpabilidad es de difícil verificación en estos casos porque cualquier decisión administrativa, como bien razona SABÁN, es más que probable que cuente con informes favorables o neutrales. En este sentido se pueden encontrar pronunciamientos jurisprudenciales que dificultan las técnicas penales contra el cohecho, la malversación o la prevaricación ${ }^{9}$. En el caso del cohecho hay que tener en cuenta que el favor que se intercambia no esté en el marco de las facultades propias del cargo público y que es necesario, no una simple abstención, sino una conducta activa. Así, por ejemplo una sentencia del Tribunal Supremo de 27 de septiembre de 1990 exime a determinados

\footnotetext{
${ }^{8}$ A. SABÁN, Op. cit, p. 69

${ }^{9}$ A. SABÁN, Op. cit, pp 71-72.
}

REVISTA DO DIREITO UNISC, SANTA CRUZ DO SUL No $41 \mid$ p. 110 - 168| NOV - DEZ 2013 
guardias civiles del delito de cohecho por "hacer la vista gorda" en un cargamento de tabaco de contrabando.

En el caso de la malversación, quedarse con el dinero que se administra o darle un destino diferente al previsto, las conclusiones según SABÁN son parecidas. Así, cita una sentencia de 21 de junio de 1990, también del Tribunal Supremo, en la que se establecen los requisitos para que opere el delito: la condición de funcionario del actor, un poder del funcionario sobre el destino de los bienes, la consideración de públicos de los caudales y una actividad dinámica de apropiación definitiva del dinero, sustrayendo o consintiendo que otro lo haga. La sentencia de 20 de septiembre de 1990 contiene exposiciones comunes a cualquier comportamiento corrupto: " traición fundamental de los deberes de lealtad, probidad y fidelidad inherente a la función pública", "desleal e innoble apetencia de los servidores de aquella función a los que, habiéndose concedido soberanía de poder, burlan la confianza en ellos depositada" ${ }^{10}$. Conviene, en mi opinión, destacar estas formulaciones del Tribunal Supremo porque, en cierta medida, suponen la recepción jurisprudencial de los principios más importantes de la Etica del servicio público y, con ello, su protección y defensa jurisprudencial.

Pero, ¿qué ocurre en los supuestos de prevaricación, en aquellos casos en los que el funcionario público dicta a sabiendas, deliberadamente, una resolución injusta?. En realidad, como escribe SABÁN, todo propósito corrupto se traduce necesariamente en un delito de prevaricación. Sin embargo, lo que ocurre es que es difícil de probar el elemento subjetivo, la intencionalidad ${ }^{11}$.

Como regla, la actividad administrativa es controlada por los tribunales de lo contencioso-administrativo. La vía contenciosa, a través de preceptos constitucionales como el de la tutela judicial efectiva, ha permitido un notable

\footnotetext{
${ }^{10}$ En el mismo sentido, la sentencia del Tribunal Constitucional de 25 de mayo de 1986, también citada por SABÁN.

${ }^{11}$ A. SABÁN, Op. cit., p. 74.

REVISTA DO DIREITO UNISC, SANTA CRUZ DO SUL No $41 \mid$ p. $110-168 \mid$ NOV - DEZ 2013
} 
avance en el sistema de control judicial de los actos administrativos. Es más, como reconoce SABÁN, el control contencioso-administrativo, no sin un importante respaldo doctrinal, deberá introducirse en el complejo mundo de los motivos y fines de la actuación pública ${ }^{12}$. Sin embargo, la actual concepción de la responsabilidad de los agentes de la Administración pública sigue siendo restrictiva tal y como señala una sentencia del Tribunal Supremo de 6 de noviembre de $1990^{13}$ cuando dice que "resulta insuficiente para responsabilizar al recaudador de una situación de perjuicio, en algunos de los grados que contempla, siendo necesaria además una actitud acreditadamente dolosa o negligente que la Administración delegante no haya tolerado ni contribuido a fomentar mediante una actuación incorrecta o de simple dejación de funciones".

En fin, se trata de un ejemplo más de la necesidad de superar el sistema contencioso como proceso al acto que se ha producido por mor de la ley de la jurisdicción contencioso administrativa de 1998 y de situar la ejecutividad administrativa en el marco de una tutela judicial cautelar, en la línea de lo dispuesto por el famoso auto del Tribunal Supremo de 20 de diciembre, del que fue ponente el profesor GONZÁLEZ NAVARRO. La ausencia de un acto impide en materia de corrupción, por la propia naturaleza del fenómeno, su control y la ejecutividad convierte en irreparables las situaciones de hecho que crea la Administración ${ }^{14}$.

Finalmente, por lo que se refiere al control de la actuación administrativa, también debe tenerse en cuenta la aplicación de la responsabilidad civil. Lo que ocurre es que la Administración es siempre quien responde por los daños ocasionados por el funcionamiento de los servicios públicos y, más tarde, puede repetir, con la barrera de la culpa o negligencia grave, frente al funcionario autor de la actuación administrativa provocadora de los daños. Hoy, tras la reforma

\footnotetext{
${ }^{12}$ A. SABÁN, Op. cit., p. 77.

${ }^{13}$ Citada por A. SABÁN, Op. cit., p. 77.

${ }^{14}$ A. SABÁN, Op. cit., p. 78.
}

REVISTA DO DIREITO UNISC, SANTA CRUZ DO SUL No 41|p. 110 - 168| NOV - DEZ 2013 
de la Ley de régimen jurídico de las Administraciones públicas y del procedimiento administrativo común efectuada en 1999, la Administración debe repetir contra el funcionario cuándo, tras en expediente contradictorio, se acredite la existencia de culpa o negligencia grave en su actuación. Sin embargo, como tal previsión legal no ha sido concretada en la pertinente norma administrativa, es inoperante y seguimos en la misma situación que en al pasado.

También, como señala acertadamente SABÁN, "es necesario buscar nuevas fórmulas, o mejorar las presentes, de control interno de la propia actividad administrativa. Ni un apagado Consejo de Estado, ni un Tribunal de Defensa de la Competencia que nos tiene acostumbrados a resoluciones por motivos de "oportunidad política", ni siquiera los prestigiosos Tribunales Económicos Administrativos han sido capaces de un auténtico control eficaz sobre la propia actividad administrativa "15.

En cualquier caso, no siempre es posible reducir a sanción jurídica todas las manifestaciones de la corrupción porque es francamente difícil desvelar, desde un punto de vista jurídico-formal, todas y cada una de las innumerables formas de corrupción, sobre todo las más sutiles. Por eso, ciertamente el Derecho puede hacer mucho, pero no es la varita mágica que arregla todos los problemas.

La cuestión de la corrupción exige introducir programas de Ética pública, no sólo en las Escuelas de Administración pública, sino también en la educación previa al ingreso en la Administración y, también, antes y durante el tiempo en el que se ocupen cargos públicos. No se trata de un planteamiento negativo en virtud del cual se trate de "convertir" a una clase funcionarial y política falta de sensibilidad pública. Se trata más bien de preservar y mejorar la calidad del servicio público. Y hoy, el ejercicio de funciones públicas, se encuentra, se quiera o

\footnotetext{
${ }^{15}$ A. SABÁN, Op. cit., pp 89-90.
}

REVISTA DO DIREITO UNISC, SANTA CRUZ DO SUL No $41 \mid$ p. 110 - 168| NOV - DEZ 2013 
no, fuertemente influenciado por los parámetros que presiden la vida social que, en muchos casos, no son los más adecuados para regir los destinos de la cosa pública. $^{16}$

La corrupción, no lo olvidemos pues ejemplos hay en algunos países, crece, crece y llega, si no se la detiene a tiempo, a ser una practica "normal". Por eso, la sensibilidad hacia lo público exige, además de una formación adecuada, el ejercicio, por parte de los funcionarios y gestores públicos, de las virtudes morales que configuran el nervio del servicio público.

No hace tiempo ${ }^{17}$ el hoy ex presidente checoslovaco Vaclar Havel, con motivo de la entrega del Premio Sonning, pronunció un discurso sobre las exigencias morales de las tareas públicas del que no me resisto a transcribir varios párrafos:

"(. . .) Resulta muy interesante observar lo diabólica que puede ser la tentación del poder. Se puede apreciar mucho mejor en aquellas personas que nunca tuvimos ningún poder y que siempre criticamos con audacia a los poderes por disfrutar de tal o cual ventaja que ahondaba la distancia entre ellos y el pueblo. Cuando de repente nos vemos en el poder, instintivamente empezamos a parecernos a nuestros despreciables antepasados. Nos molesta, nos irrita, pero verificamos que no somos capaces de resistirnos.

Pero ¿dónde termina la lógica y la necesidad objetiva y empiezan los pretextos? (. . ¿) ¿Es que acaso conocemos y sabemos discernir el instante en que ya no se trata del interés del país, al que nos sacrificamos tolerando nuestras ventajas, y se trata ya de nuestras ventajas, que disculpamos hablando del interés del país?.

\footnotetext{
${ }^{16}$ En cualquier caso, la necesidad de Etica para los asuntos públicos ha sido frecuente noticia últimamente en los medios de comunicación.

${ }^{17}$ Vid. Blanco y Negro, 23 de junio de 1991.
}

REVISTA DO DIREITO UNISC, SANTA CRUZ DO SUL No $41 \mid$ p. 110 - 168| NOV - DEZ 2013 
Confieso que se necesita tener un nivel elevado de reflexión y de autocrítica para ser capaz de identificar este instante, por muy buenas que hayan sido anteriormente las disposiciones. Yo mismo, que lucho constantemente, y con escaso éxito, contra las ventajas de que gozo, no me atrevería a afirmar que soy capaz de discernir siempre y con seguridad este momento. El ser humano se acostumbra, se desacostumbra, y a la postre -sin darse ni siquiera cuenta- puede perder su comprobado sentido crítico.

(...) De todo esto se deduce que la política es un sector de actividades humanas que plantea mayores exigencias al sentimiento moral, a la capacidad de entender el alma de los otros, al sentido de la medida y de la humildad. Es una dedicación para personas que no se dejan engañar.

Todos los que afirman que la política es un sector de actividades humanas que plantea mayores exigencias al sentimiento moral, a la capacidad de autorreflexión crítica, a la verdadera responsabilidad, al buen gusto y al tacto, a la capacidad de entender el alma de los otros, al sentido de la medida y de la humildad. Es una dedicación para personas que no se dejan engañar.

Todos los que afirman que la política es un asunto sucio mienten. La política es sencillamente un trabajo que requiere personas especialmente puras, porque resulta muy fácil caer en la trampa. Una mente poco perspicaz ni siquiera se dará cuenta. Por lo tanto, tienen que ser personas especialmente vigilantes las que se dediquen a la política, personas sensibles al doble sentido de la autoconfirmación existencial que de ella se desprende.

Ignoro totalmente si pertenezco al grupo de personas vigilantes. Sólo sé que debería pertenecer, ya que acepté mi cargo".

REVISTA DO DIREITO UNISC, SANTA CRUZ DO SUL No 41|p. 110 - 168| NOV - DEZ 2013 
Sabemos que corrupción y poder normalmente van siempre unidos. El abuso, o el mal uso del poder, sea público o privado, es causa de corrupción. El poder, lo sabemos bien, tiende a expandirse y, lo que es peor, el afán de poder, si no se modula, lleva ya aparejado el germen de la corrupción.

Es verdad que la idea democrática surge, entre otros factores, para poner coto a través de la razón a la desmedida tendencia al abuso del poder público que caracteriza, guste o no, a la naturaleza humana. Las relaciones, en este sentido, entre democracia y corrupción son antiguas ${ }^{18}$. Sin embargo, en estos años, han sido analizadas desde distintos puntos de vista para llamar la atención sobre algo que hoy parece incontestable: que la democracia no garantiza sin más la erradicación de la corrupción, y lo que es más grave: que el falseamiento de la idea democrática contribuye enormemente a difundir una clara cultura "pro corruptione" 19

También se ha ocupado de esta cuestión MONTANELLI, para quien uno de los peores dramas de la situación italiana es que quienes cuidan de la Administración pública ya no son funcionarios con una clara conciencia del servicio público sino empleados de los partidos políticos que, en lugar de contribuir al control, aprovechan su posición para colaborar, escribe MONTANELLI, en las "razzias" de los partidos políticos. Que esto ocurra trae su causa de una evidente prostitución de la democracia que se entrega al dominio de unos partidos políticos que sólo se justifican como máquinas de influencia y de compra y venta de votos ajenos, eso sí, aprovechándose de las legítimas aspiraciones y deseos de un pueblo que, al final, no es más que la excusa para seguir practicando toda una serie de "desaguisados" y "barbaridades" en nombre, y al servicio, de la idea democrática.

\footnotetext{
${ }^{18}$ Cfr. S. ROSE-ACKERMAN, Corruption: a study in Political Economy, New York, 1978, pp. 17 y ss.

${ }^{19}$ Vid. R. CALDERA, Democracia y corrupción, ABC, 23.IX.1992, p. 8; I. MONTANELLI, Democracia y corrupción, La Vanguardia, 13.X. 1995, p. 12; J.F. REVEL, La corrupción corroe las democracias, El Mundo, 31.I.1992, p. 4; M. RAMIREZ, Democracia y corrupción, Diario 16-G, 19.I.1992, p.21 y, en general, A. PIZZORNO, La corruzione del sistema político, en D. DELLA PORTA, Lo scambio occulto, Roma, 1992, pp. 5 y ss.
}

REVISTA DO DIREITO UNISC, SANTA CRUZ DO SUL No $41 \mid$ p. $110-168 \mid$ NOV - DEZ 2013 
El intelectual francés REVEL escribió en 1992 un interesante libro titulado "La renovación democrática" que trata de la caída del bloque comunista y que es un alegato a favor de una forma de entender la democracia como un mínimo vital que, junto al mercado y a los derechos humanos, ha funcionado como revolución moral contra el gigantesco campo de ruinas políticas, económicas, sociales y morales de los modelos comunistas y sociales. REVEL es especialmente claro al tratar de la corrupción: cuando las costumbres se degradan, la democracia se aparta, entonces, de su vocación propia, se desnaturaliza.

El catedrático de Derecho Político español Manuel RAMíREZ también analizó no hace mucho estas cuestiones al tratar del sentido de la democracia y las causas de su irrupción como forma de gobierno. La clave hay que buscarla en que la democracia no se consolida sin esfuerzo: hace falta trabajo, hacen falta hábitos; en definitiva, un talante en el que, gracias al impulso democrático, se estimula que la ciudadanía piense, que tenga capacidad crítica y que aspire a los auténticos valores democráticos. Y quizás no se está promoviendo ni fomentando este esfuerzo, sino todo lo contrario. De ahí que sea tan importante proteger el sistema democrático, pero el verdadero, no esta falseada versión en la que parece que la democracia es igual a indiferencia, a apatía, a ley del mínimo esfuerzo y éxito a cualquier precio.

La democracia es algo más que un sistema de gobierno, es, sobre todo un estilo de vida, una manera de estar en la sociedad. Manuel RAMíREZ ha señalado certeramente que, en los últimos años, la democracia se ha reducido exclusivamente a una forma de gobierno ${ }^{20}$ que, es lo más grave, ha traído consigo modelos de conducta en franca oposición con lo que es la idea democrática. Por eso, una sociedad que no ha asumido los valores democráticos y cuya cultura cívica

${ }^{20}$ M. RAMÍREZ, Corrupción y sociedad, El País, 6.VI.1994, p. 14.

REVISTA DO DIREITO UNISC, SANTA CRUZ DO SUL № $41 \mid$ p. $110-168 \mid$ NOV - DEZ 2013 
sigue siendo endeble es un caldo de cultivo propicio para la corrupción. $Y$, lo más grave es que los ciudadanos empiezan a desconfiar, como regla, de los políticos. Esto es bien penoso y exige remedios a corto plazo aunque, bien pensado, como señala el profesor RAMíREZ, la solución debe venir de la educación en los valores democráticos y en una cultura cívica que enseña a no engañar al Estado porque se percibe como algo propio, que enseñe el valor del diálogo, el sentido de la responsabilidad, la condena de la mentira, la primacía de las virtudes públicas y, sobre todo, una convivencia basada en un sólido ejercicio de virtudes morales, porque, sin el compromiso personal y la asunción de la idea moral en el plano personal, todo quedará en grandes discursos, pero todo seguirá igual en la práctica de cada día.

En estos años, de profunda corrupción a causa de la honda crisis moral que nos embarga, existe el peligro de que se enarbole desde un punto de vista agresivo la bandera de la moralización de la vida pública como arma arrojadiza. Ciertamente hoy la Ética pública es más necesaria que en otros momentos, pero no es menos cierto que la Ética política actual no es sólo, aunque es su presupuesto, ejercicio de virtudes y cualidades democráticas. Ser honesto, íntegro e imparcial son virtudes básicas para el ejercicio del poder, pero hoy se necesita que los hombres públicos sepan manejarse en supuestos de complejidad creciente y que sepan interpretar, dice INNERARITY, las nuevas responsabilidades que llevan consigo los acelerados cambios sociales y políticos. Hoy, es necesaria una mayor sensibilidad hacia los derechos humanos, un mayor respeto a las minorías, una mayor conciencia ecológica y una mayor operatividad del concepto de la dignidad de la persona.

\section{B.- DELIMITACIÓN CONCEPTUAL}

REVISTA DO DIREITO UNISC, SANTA CRUZ DO SUL No 41|p. 110 - 168| NOV - DEZ 2013 
Sabemos muy bien que el término "corrupción" admite distintas aproximaciones tal y como ocurre con cualquier realidad compleja ${ }^{21}$. Sin embargo, existe un denominador común: la utilización en provecho propio, familiar, de grupo o facción, de las potestades públicas ${ }^{22}$ en caso de estudiar esta cuestión en el marco del sector público.

Normalmente, cuando se trata de la corrupción, inmediatamente se asocia con determinadas conductas de responsables y funcionarios públicos. Efectivamente, el profesor de Harvard NYE en 1967 definía la corrupción como una conducta personal que supone una desviación o infracción en el cumplimiento normal de las normas de la función pública a causa de beneficios económicos para uno o sus allegados. En esta definición se incluye el soborno (utilización de recompensas para condicionar las decisiones políticas o administrativas), el nepotismo o la prevaricación ${ }^{23}$. En realidad, lo decisivo para que pueda hablarse de corrupción pública es que la actuación merecedora de tal calificación sea realizada por quien está investido de poder público y que beneficie al funcionario o responsable o a personas próximas. En la aproximación de NYE no se contempla la posibilidad, nada infrecuente, de que la finalidad de la conducta sea beneficiar al partido político en el que milita el funcionario o cargo público. Es el supuesto, por ejemplo del famoso caso "Watergate". Pero no es esta la única limitación de la definición del profesor de Harvard, porque su aportación podría interpretarse en función de lo que es "cumplimiento normal" en unos países o en otros y teniendo en cuenta que no en todos los lugares hay codificaciones éticas, ni están sancionadas

\footnotetext{
21 Vid. Z. BREI, Corrupçao: dificuldades para definiçao e para um consenso, RAP (Brasil), vol. 30, 1996, pp.64 y ss.

22 Vid. J. MALEM, Acerca del concepto de corrupción, en FLAPORTA-S. ALAREZ, Op. Cit., pp. 39 y ss. y A. NIETO, Corrupción en España democrática, Barcelona, 1997, pp. 76 y ss.

23 Vid. J.A. GARDINER, Definir la corrupción, V Congreso Internacional contra la corrupción, Amsterdam, 1992, Manuscrito. Además, P. DOBEL, The corruption of a State, American Political Science Review, 1978, p. 65.
} 
estas prácticas. Sin embargo, es conveniente señalar que no es posible -ni justoque la corrupción no esté condenada en todas partes del mundo.

En efecto, en muchos lugares, sobre todo del entorno subdesarrollado, es normal que los cargos electos y de designación mezclen los intereses públicos con los intereses particulares. A pesar de ello, hay que comentar que mientras se tolere que el cumplimiento normal de las obligaciones de un funcionario incluya la aceptación de regalos o la admisión de los conflictos de interés, la lucha contra la corrupción seguirá siendo una ilusión. Es más, como plantea GARDINER, i es admisible que un contratista invite a la Riviera francesa de vacaciones a un jefe de compras de la Administración y a su familia ? o, ¿ está permitido que el Ministro de Obras Públicas otorgue un contrato a una empresa que es, en parte, propiedad suya ?. La respuesta es no. Y, ambas conductas, responden a lo que comúnmente se entiende por corrupción pública: uso de potestades públicas en beneficio propio ${ }^{24}$.

Otra aproximación a la corrupción, igualmente interesante, es la que parte, como señala GARDINER, del abuso de poder por parte de los responsables y funcionarios públicos. En este contexto, corrupción es igual a mal uso de las potestades públicas, aproximación más amplia que la del profesor NYE y que, por ello, permite superar las limitaciones de una definición tan estricta. En opinión del politólogo GIBBONS, bajo esta rúbrica, se encuentran el nepotismo, el clientelismo, el conflicto de intereses legislativo y el conflicto de intereses administrativo ${ }^{25}$. El nepotismo, como su propio nombre indica, se refiere a que los responsables 0 funcionarios públicos adjudiquen puestos en la Administración pública a familiares o amigos en lugar de a quien en justicia le corresponde. El clientelismo, según GIBBONS, hace referencia al nombramiento o, en su caso cese, para los puestos públicos de personas próximas o del partido político en el Gobierno a quienes se debe recompensar por los servicios prestados. El conflicto de intereses legislativos,

\footnotetext{
${ }^{24}$ Ibidem

${ }^{25}$ Ibidem
}

REVISTA DO DIREITO UNISC, SANTA CRUZ DO SUL No 41|p. 110 - 168| NOV - DEZ 2013 
por su parte, se refiere a aquellos supuestos en que los diputados tengan acciones de empresas que son objeto, previa votación, de determinados beneficios fiscales. $\mathrm{Y}$, el conflicto de intereses administrativos, como su propio nombre indica, se refiere a casos en los que los altos funcionarios utilizan conocimientos y contactos propios de su actividad pública para actividades empresariales. Es interesante destacar, como hace GARDINER, que la corrupción más fácil de detectar es la que conculca las normas pero no es la más grave ${ }^{26}$. Quizá la versión más grave de la corrupción sea ese conjunto de prácticas que, sin ser contrarias formalmente a la ley, suponen un claro atentado a la conducta que cabe esperar de los funcionarios y a la imagen misma del funcionamiento de las Administraciones democráticas.

El profesor GARDINER establece un tercer grupo de supuestos de "corrupción": se trata de prácticas comerciales irregulares, fraudes, robos, abusos y despilfarros. La diferencia de estos casos con relación a la "corrupción" -tal como la entiende NYE- y al abuso de poder se encuentra en que estas prácticas son cometidas por personas que, ni son funcionarios, ni están investidos de cargos públicos. Sin embargo, en este momento, no nos interesan tanto estos supuestos sino el fenómeno, en si mismo considerado, de la corrupción en el ámbito público ${ }^{27}$.

La definición del término corrupción no es sencilla porque, entre otras cosas, es necesario enfrentarse con la cuestión relativa a los criterios que se utilizan para establecer las normas de conducta a las que deben ajustarse los funcionarios. Desde una perspectiva formal o jurídica es obvio que sólo existirá corrupción si se vulneran las normas jurídicas. Es la corrupción "ilegal"; pero puede haber, y es la que más abunda, corrupción o prácticas corruptas no prohibidas expresamente por

\footnotetext{
${ }^{26}$ Ibidem. Además, este autor, sitúa dentro del abuso de poder los supuestos de concesión de contratos oficiales a amigos políticos, las mentiras ante los medios de comunicación y algunas formas de financiación de campañas electorales.

27 Vid. también, R.J. WILLIAMS, Political corruption in the United States, Political Studies, 1981, March, pp. 126 y ss o A. ETZIONI, capital corruption: the new attack on American democracy, New York, 1984, pp. 3 y ss.
}

REVISTA DO DIREITO UNISC, SANTA CRUZ DO SUL No $41 \mid$ p. $110-168 \mid$ NOV - DEZ 2013 
la ley. Por eso, el politólogo de la Universidad de Yale, SCOTT, es partidario de las codificaciones éticas ya que permiten perseguir mejor las conductas corruptas, amén de que, funcionarios y ciudadanos tengan más claro el marco de actuación.

En cualquier caso, no deja de llamar la atención la atinada consideración del profesor SCOTT cuando nos advierte que uno de los peligros de la definición jurídica de corrupción puede ser que permita identificar lo legal con lo ético. Sobre este extremo ya hemos dado nuestro punto de vista puesto que, en muchos casos, la complejidad de las normas jurídicas, no sólo no es un arma eficaz para luchar contra la corrupción, sino que es una fuente de prácticas irregulares. Pero no es este el único peligro de las aproximaciones jurídicas al problema de la corrupción, pues no se debe olvidar que es posible, y real, que una acción en un país sea formalmente corrupta y en otro no lo sea. Es un problema, éste, no pequeño. Su solución pasa por un acuerdo general, que es urgente, sobre los principios del servicio público, principios que son universales $\mathrm{y}$, por tanto, susceptibles de aplicación a todos los países.

Pero además de las definiciones jurídicas, sobre las que más adelante volveremos, GARDINER plantea la aproximación al concepto de corrupción desde la idea del interés general, desde la perspectiva del bien común. Las dificultades para instaurar un concepto jurídico de corrupción hemos comprobado que son serias. Porque puede haber actos ilegales que sean éticos si la ley es una ley injusta, y puede haber casos de actos ilegales que pueden ser corruptos. Casos hay muchos en la historia pero los que elige GARDINER son francamente buenos y plantean cuestiones de amplio calado en este tiempo que nos ha tocado vivir.

Dos ejemplos, ¿ que se podría pensar de un soldado nazi que, en contra de la norma que prohibía la emigración judía, autorizaba salidas de judíos por una cantidad de dinero ?. Se trata de un acto ilegal, y corrupto formalmente. Ahora № 41|p. 110 - 168|NOV - DEZ 2013 
bien, el problema de este supuesto es que el soldado debería autorizar la salida de judíos sin necesidad de obtener un beneficio económico a cambio. El otro supuesto, el de actos legales que pueden producir los efectos específicos de la corrupción: que se favorezca a determinados grupos. El caso es, como el anterior, delicado. Se trata de examinar la conducta de funcionarios que, entre 1950 y 1960 en EEUU tuvieron que aplicar el llamado programa "Renovación urbana". Programa que, en síntesis, buscaba evitar la degeneración de los centros urbanos a través de un complicado sistema de expropiaciones, derribo de edificios y venta de solares a promotores inmobiliarios. Lo que pasó es que muchos de estos solares estaban ocupados por gente pobre y perteneciente no pocas veces a minorías étnicas que veían como después de la expropiación y derribo, surgían grandes y lujosos edificios de pisos y oficinas. El problema para los funcionarios que debían aplicar este programa no era sencillo pues se producían situaciones injustas independientemente de si los beneficios económicos del Programa eran elevados. La cuestión es si la economía está o no al servicio del hombre y si los funcionarios pueden o no abstenerse de actuar cuando piensen en conciencia que pueden colaborar a la degradación de la dignidad de la persona. En este supuesto es evidente que se estaba favoreciendo a las clases medias y medio altas de los EEUU a costa de los pobres y de las minorías porque el acto de los funcionarios podría, formalmente, calificarse de corrupto, y sin embargo ser legal.

Estos ejemplos son bien ilustrativos. Por una parte permiten pensar en la necesidad de formación ética para los funcionarios y, por otra, plantean también hasta que punto los responsables públicos pueden de verdad contribuir a luchar a favor de la dignidad humana. Y, por otro lado, quizá el más interesante en este momento, esta situación plantea la necesidad de buscar otras definiciones de corrupción que vayan más allá de la legalidad. Así ha surgido la aproximación a la corrupción desde la perspectiva del interés público, del interés general, del bien 
común porque me parece que el interés público, el interés general, es la versión jurídico-administrativa del concepto procedente de la Ética social.

Si un acto va contra el interés público, contra el interés general, que es un concepto más amplio como he intentado demostrar en mi libro sobre "Interés general, Estado de Bienestar y Derecho Administrativo" es corrupto aunque sea legal. $O$, si se quiere, si potencia los derechos fundamentales de los ciudadanos, no es un acto corrupto aunque sea ilegal ${ }^{28}$. Es obvio que en esta aproximación hacia lo que debe ser el interés general, el interés público, debo manifestar que, en mi opinión, el interés público, el interés general, está vinculado a la promoción de los derechos humanos de todos los ciudadanos como consecuencia de lo que debe entenderse por bien común. Es decir, interés general, interés público en sentido amplio es igual a dignidad de la persona. Desde este punto de vista, pues, el soldado nazi no podría prohibir la salida de judíos por motivos de "interés público" pues estaría conculcando un derecho humano fundamental. Y, en el mismo sentido, el funcionario encargado de aplicar el programa de "renovación urbana" estaría, en aquellos supuestos en que fuera palmario, impidiendo el derecho humano a una vivienda digna.

La historia demuestra que no siempre el resultado de los procesos políticos ha supuesto progreso en el desarrollo de los derechos humanos. Ahora bien, la aproximación a la corrupción desde el punto de vista del interés general, del interés público en sentido amplio, ayuda a entender el fenómeno y, en todo caso, proporciona unas importantes modulaciones al concepto jurídico de corrupción.

Sin embargo, GARDINER todavía nos ofrece una tercera aproximación conceptual a la corrupción. Se trata de la perspectiva de la opinión pública. Más que un criterio válido de definición, las relaciones entre corrupción y opinión pública

\footnotetext{
${ }^{28}$ Ibidem
} 
permiten plantear mejor la fuerza necesaria para luchar contra la corrupción. ${ }^{29}$. Porque, como dice GARDINER, si existen discrepancias sustanciales entre lo que establecen las leyes y la idea de la corrupción que tienen la mayoría de los ciudadanos, los funcionarios y magistrados serán más propensos a guiarse por la cultura popular. Si los magistrados y fiscales saben que a los ciudadanos les preocupa la corrupción porque exigen un patrón elevado de honradez y ejemplaridad ética, entonces estarán más predispuestos a iniciar investigaciones y a ser inflexibles en las sentencias. Y, desde el punto de vista de los ciudadanos comprometidos con la limpieza y la honestidad, es claro que se tenderá a elegir personas con reputación ética.

Es pues, interesante, la aproximación a la posición de los ciudadanos. Veamos. Es conocida la división del profesor HEIDENHEIMER en corrupción negra, gris y blanca en función del grado de rechazo ciudadano a las prácticas de corrupción. La negra alude a la situación de consenso general sobre la necesidad de condenar y perseguir en todo caso la corrupción. En la corrupción "gris", algunos sectores de la población, generalmente pertenecientes a la élite, son tolerantes. En los casos de corrupción blanca, la mayoría de los ciudadanos probablemente no serán partidarios de castigar rigurosamente una modalidad de corrupción que entienden como tolerable al pensar que, más importante que los valores, son los costes que podrían resultar de un cambio sustancial en la aplicación de las normas.

Toda clasificación casi siempre es, cuando menos, polémica. Y esta, también. Por ejemplo, es sabido que las actitudes durante un período de tiempo son fluctuantes. JOHNSTON, profesor de la Universidad de Colgate ${ }^{30}$ demuestra como, antes y después del "Watergate", los sondeos de opinión en EE.UU. mostraban una preocupación por la integridad de los cargos públicos superior a la registrada

\footnotetext{
${ }^{29}$ Ibidem

${ }^{30}$ Ibidem
}

REVISTA DO DIREITO UNISC, SANTA CRUZ DO SUL No $41 \mid$ p. $110-168 \mid$ NOV - DEZ 2013 
anteriormente. Pero también es cierto que después de la dimisión de NIXON, el grado de preocupación volvió a disminuir. La pregunta que surge de este caso es evidente: ¿ En qué momento se puede detectar mejor la opinión del público sobre la corrupción ? Quizás lo más importante es saber que, en momentos de crisis moral, como el actual, la opinión general sea de gran preocupación pues., en condiciones normales, los ciudadanos darán más importancia a otros asuntos.

¿Qué piensan, en general, los ciudadanos sobre la corrupción? ${ }^{31}$. Es una pregunta no fácil de responder. Sin embargo, con las cautelas propias de quien sabe que las encuestas no equivalen a la verdad, el profesor GARDINER nos comenta un estudio suyo, de 1966, en el que se plantea la opinión de la población de una ciudad norteamericana en la que los representantes electos y altos funcionarios de policía eran "colocados" por un siniestro sindicato del crimen. La encuesta de GARDINER no demostró que se aceptase la corrupción aunque si puso de relieve una absoluta tolerancia en relación con el juego, a la sazón fuente de ingresos del sindicato del crimen. La encuesta, además, demostró que un número nada despreciable de ciudadanos toleraban algunas formas de corrupción como hacer caso omiso de los conflictos de interés o la aceptación de regalos de empresas. Sin embargo, la mayoría de la población de esta ciudad, como no podía ser menos, eran partidarios de la honradez y de la aplicación de la ley contra las prácticas corruptas ${ }^{32}$.

Más interesante, si cabe, es la encuesta realizada por los politólogos PETER y WELCH el juicio que les merecía a cuatrocientos diputados de distintos Estados determinados casos de corrupción ${ }^{33}$. Las conclusiones a dicha encuesta

\footnotetext{
${ }^{31}$ Ibidem

${ }^{32}$ Ibidem

${ }^{33}$ Se trataba de:
}

1) un candidato a Presidente que promete un cargo a cambio de ayudas económicas para una campaña electoral,

2) un congresista que utiliza su cargo para conseguir un contrato de armamento para una empresa de su propia circunscripción,

3) un cargo público que utiliza fondos públicos para viajes privados,

REVISTA DO DIREITO UNISC, SANTA CRUZ DO SUL $\mathrm{N}^{\circ} 41 \mid$ p. $110-168 \mid$ NOV - DEZ 2013 
hay que ponerlas en relación con el cargo público, el donante, el favor que se hace y su "recompensa". Los datos recogidos en la citada encuesta permiten afirmar que una acción es más "corrupta" si el cargo público que aceptaba condicionar su decisión ocupa un puesto no-político, juez por ejemplo, y si se realiza en el marco estricto de su actividad pública. En relación con el donante, PETERS y WELCH señalan que el acto se consideraba menos "corrupto" si el diputado en cuestión recibía fondos de una persona de su distrito electoral. Sin embargo, actuar por "precio" distinto del sueldo es un claro caso de corrupción, sea más o menos tolerado por los ciudadanos.

La tercera variable se refiere al favor prestado. En estos supuestos, la acción será tanto más corrupta si el dinero es privado, si el destinatario era de fuera del distrito electoral o si era un acto extraordinario. En todo caso, la corrupción también en este supuesto es clara y no deja lugar a dudas.

En relación con la recompensa, o el "precio" por la actuación, también la encuesta admite supuestos de más o menos corrupción. Sin embargo hay que señalar que la corrupción no se produce por la mayor aceptación popular de determinadas acciones, sino por la desnaturalización de las potestades públicas que implica usar los poderes para fines de interés distintos al público ${ }^{34}$.

4) un alto cargo de defensa que tiene una participación accionarial importante de una empresa con la que el Departamento de Defensa tiene un contrato millonario,

5) un cargo público que aprovecha su condición para que un familiar o amigo sea admitido a una Facultad Universitaria,

6) un alcalde que asfalta una pista interna de su finca usando la brigada municipal,

7) un diputado que siendo presidente de la Comisión de Obras públicas autorice la compra de unos terrenos que acababa de adquirir,

8) un juez que falla en un caso en que está implicada una empresa en la que él tiene una participación importante,

9) un diputado que acepta una ayuda económica para su campaña electoral a cambio de votar de forma determinada en la votación de un proyecto de ley,

10) un diputado con una participación muy importante en una conocida empresa petrolífera que hace campaña a favor del mantenimiento de la subvención a dicha compañía por agotamiento de las reservas petrolíferas.

${ }^{34}$ Curiosamente, estos resultados, como señala GARDINER son casi los mismos a los que llegaron ATKINSON y MANCUSO después de encuestar a diputados del Parlamento canadiense en 1985.

REVISTA DO DIREITO UNISC, SANTA CRUZ DO SUL $\mathrm{N}^{\circ} 41 \mid$ p. $110-168 \mid$ NOV - DEZ 2013 
En fin, la aproximación ciudadana a la corrupción permite subrayar la importancia que tiene la formación ética, tanto de los responsables públicos como de los ciudadanos en general. El profesor GARDINER señala que el trabajo en este sentido de la Comisión Independiente contra la corrupción de Hong-Kong es bien importante pues ha ido consiguiendo, poco a poco, sensibilizar a los ciudadanos y, lo que es más difícil, cambiar actitudes a través de un ambicioso programa educativo en las escuelas, trabajo con asociaciones, presencia en televisión, difusión del estatuto para la prevención del soborno, etc. La educación y la cultura de servicio público son, quizás, los mejores antídotos contra la corrupción. Como lo es también el intento, pese a las distintas legislaciones y culturas, de aproximación de la corrupción desde la perspectiva de un interés público vinculado a la promoción de los derechos humanos de todos los ciudadanos en el contexto del bien común.

Desde el punto de vista de la teoría política, Herbert H. WERLIN publicó en el número cuatro de 1994 de la Revista del Instituto Internacional de Ciencias Administrativas un interesante trabajo sobre la definición de la corrupción. Cuestión que, después de lo que llevamos escrito puede afrontarse, por ejemplo, desde la posición aquí defendida del interés general, del interés público en sentido amplio. De todos modos, como escribieron en 1983 GOULD y AMARO REYES, no existe ninguna definición de corrupción que haya sido objeto de aprobación general, lo que no quiere decir que sea una tarea imposible. En mi opinión la aproximación al interés general, al interés público en sentido amplio desde la orientación de la dignidad de la persona humana y del bien común es útil y soluciona muchos problemas.

WERLIN parte en su análisis de los dos aspectos básicos que configuran el concepto de la política. A saber, la relación entre gobernantes y ciudadanos y, por otra parte, la lucha por reconciliar la tentación del partidismo con 
el seguimiento de los intereses públicos en sentido amplio. Pues bien, la causa propia de la corrupción se encuentra precisamente en la tensión entre el partidismo y el interés general. Y esta tensión, que es universal, se ha dado y se dará siempre, se orienta a la corrupción cuando un elemento prima sobre el otro, cuando el espíritu partidista domina al hombre de Estado. Entonces se produce la degradación del poder tal como explica CAIDEN en su conocida definición elemental ${ }^{35}$ que es la característica fundamental de la corrupción: conversión de la finalidad pública implícita en los poderes y potestades en objetivos impropios, bien sean personales 0 de grupo. La definición elemental es interesante pero insuficiente si se pretende buscar una aproximación general al margen de las coordenadas del tiempo y del espacio.

La conceptualización elemental de CAIDEN describe el efecto fundamental de la corrupción pero, en opinión de WERLIN, no puede considerarse de ámbito general porque no gradúa la cualificación moral de las acciones. Ciertamente, dentro de las conductas corruptas puede haber una mayor o menor gravedad ${ }^{36}$ pero lo que no debe admitirse es que un acto corrupto, aunque sea de pequeña entidad, no reciba esta calificación. La corrupción, es verdad, admite una tipología ${ }^{37}$ pero siempre constituye una degeneración o desnaturalización de lo que debiendo ser público se transforma en particular, familiar o de grupo o facción. Como señala CAIDEN, cualquier forma de corrupción es una traición al bien común a cambio de algo que siempre tiene mucho menos valor ${ }^{38}$.

La mayoría de los autores que se han ocupado del problema de la definición de la corrupción como HEIDENHEIMER, JOHNSTON y LE VINE la

\footnotetext{
${ }^{35}$ Vid. G.E. CAIDEN, Toward a general theory of official corruption, Asian Journal of Public Administration, $\mathrm{n}^{\circ} 10$, pp. 3-20.

${ }^{36}$ Vid. J.S. PETERS/S. WELCH, Political corruption in America: search for definitions and a theory, American Political Science Review, 1978, no 1978, nª 72, pp. 974-984.

${ }^{37}$ Vid. A.J. HEIDENHEIMER, The context of analisis, en Political corruption: reading in comparative analysis, New York, 1970.

${ }^{38}$ G.E. CAIDEN, loc. cit.
} 
clasifican como uso abusivo de un cargo público para un interés privado, como la concesión de dinero o favores para la obtención de influencias o poderes y como la violación de los intereses generales o de las normas de comportamiento para la obtención de determinados beneficios o para la consecución de fines particulares. El común denominador es la desnaturalización de lo público, la utilización de lo público para fines que traicionan su finalidad. Es claro que esta configuración conceptual es clave en el entorno de los países desarrollados. Pero en los subdesarrollados WERLIN nos dirá que la percepción general es distinta porque los sistemas políticos favorecen, o incluso exigen, comportamientos corruptos: si se piensa que los cargos públicos sirven para el enriquecimiento personal, "es normal" la práctica del nepotismo y clientelismo y, en fin, lamentablemente los intereses públicos no están por encima de los privados. En estos supuestos, es necesario contribuir a que, poco a poco, se inicien procesos culturales y formativos dirigidos a luchar contra la corrupción que, aunque sea normal, no deja de ser un claro atentado contra los derechos humanos de la población.

Las relaciones política-Administración o poder político y Administración pública constituyen un marco importante para la delimitación conceptual de la corrupción ${ }^{39}$.

Efectivamente, cuando se produce su mezcla o simbiosis y la Administración no ejecuta las políticas públicas desde criterios de imparcialidad, neutralidad y objetividad, entonces la corrupción está servida. Desde el punto de vista de la ciencia política WERLIN se muestra pesimista, ya que entiende que los funcionarios se mueven por la necesidad de obtener beneficios personales, lo cual supone que se desvian los fondos públicos hacia asuntos privados porque, siguiendo a MAQUIAVELO, ¿ por qué alguien aceptaría el peso y las responsabilidades de la dirección de la cosa pública si no es por los beneficios

\footnotetext{
${ }^{39}$ Vid. D.W. MARTIN, The fading legacy of Woodrow Wilson, Public Administrative Review, 1988, $\mathrm{n}^{\circ}$ 48, pp. 631-636.

REVISTA DO DIREITO UNISC, SANTA CRUZ DO SUL № 41|p. 110 - 168| NOV - DEZ 2013
} 
personales que pueden obtener ?. Para WERLIN, los funcionarios tienen el deber, especialmente los altos funcionarios que viven en el proceloso mundo de la discrecionalidad administrativa, de ser muy sensibles ante los derechos de los ciudadanos. Ciertamente, no se debe olvidar la tendencia natural del ser humano pero pienso que es posible volver a recuperar la fuerza del servicio público y la ilusión por la realización de trabajos colectivos que no producen más satisfacción o beneficio personal que la de contribuir a la consecución de intereses públicos y sociales que permitirán que los ciudadanos vivan en un contexto de paz, de libertad y de prosperidad. En este sentido, la Ética pública juega un papel muy importante pues hace falta que se dignifique la idea que se tiene del cargo público, o privado, y que se incida más en la vocación de servicio a los ciudadanos.

Desde otro punto de vista WERLIN señala que tanto el modelo capitalista salvaje como el socialista fomentan la corrupción ${ }^{40}$. Ya que, como escribió ECKER en 1981, la corrupción es un mecanismo de intercambios donde el poder atrae a la riqueza a cambio de tratos preferenciales ${ }^{41}$. En el caso del capitalismo porque la tendencia a la explotación del hombre es obvia y, en el caso del sistema socialista, hoy en ruinas, porque la corrupción, sentencia TARKOWSKI, seguirá siendo la principal señal de identificación de la vida política, social y económica de un mundo con economías de penuria ${ }^{42}$.

El poder corrompe y el poder absoluto corrompe absolutamente. Esta máxima de Lord ACTON, muy conocida y citada, nos induce a pensar que el cambio en la concepción de lo que debe ser el poder, tema que hemos tratado al analizar la

\footnotetext{
${ }^{40}$ Recientemente, H. WERLIN, The concept of secondary corruption, international Revieu of Administrative Sciencs, vol. 66, 2000, pp. 181 y ss.

${ }^{41}$ V. ECKER, On the origins of corruption: incentives in Nigeria, The Journal of Modern African Studies, 1981, no 19 , pp. 173-182.

${ }^{42}$ J. TARKOWSKI, Old patterns and new trends of corruption in the era of reforms: the case of Poland and the Soviet Union, Washington, XIV IPSA World Congress, 1988.
}

REVISTA DO DIREITO UNISC, SANTA CRUZ DO SUL $\mathrm{N}^{\circ} 41 \mid$ p. $110-168 \mid$ NOV - DEZ 2013 
Ética política, es una de las formas más acuciantes de luchar contra la invasión mercantilista y materialista que hoy todo lo reduce a dinero, notoriedad y poder. Hoy, me temo que asistimos a una época de la historia en la que, por las razones comentadas, la corrupción ha hecho acto de presencia con gran fuerza al haber encontrado un contexto bien abonado por una crisis moral honda y profunda sin precedentes. En Europa, paradójicamente, el propio Estado del Bienestar en su versión más estática ha alimentado, por sorprendente que parezca, una sórdida corriente de corrupción. Es más, el intervencionismo ha alimentado y estimulado a no pocos dirigentes a someterse a la adoración del dinero y del poder. Es, en efecto, un contrasentido, pero pienso que es parte de lo que viene pasando.

El profesor SILVA publicó un interesante trabajo sobre la aproximación a la corrupción en el número 28 de la Revista Brasileña de Administración pública que edita la prestigiosa Fundación Getulio Vargas. En su estudio SILVA señala que la principal característica de la corrupción es la de ocultamiento de lo público para favorecer elementos personales o de grupo. Ya sabemos que hay varios criterios para la definición: el jurídico supone la conculcación de normas, el moral alude a la intención o comportamiento de la persona. Los revisionistas, con quienes manifiesto mi desacuerdo, encuentran en la corrupción una posibilidad de beneficio, sobre todo en el caso de países subdesarrollados ${ }^{43}$. Aunque en términos económicos la corrupción trajera consigo beneficios no deja de ser reprochable pues toda corrupción, por su propia naturaleza, produce un atraso o estancamiento en el ejercicio de los derechos humanos de los ciudadanos de cualquier país.

En realidad, la definición funcional del profesor SILVA se encuentra en la línea de la aproximación que desde el interés general-derechos humanos hemos defendido. Para SILVA la corrupción es el desvío de un modelo de conducta institucionalizado que se caracteriza principalmente por la utilización de lo público ppr el sector privado con un manifiesto propósito de favorecimiento personal o

\footnotetext{
${ }^{43}$ Vid. A. BATISTA, Corrupçao. Fator de desenvolvimiento, Sao Paulo, 1991.
}

REVISTA DO DIREITO UNISC, SANTA CRUZ DO SUL No $41 \mid$ p. 110 - 168| NOV - DEZ 2013 
grupal. La esencia de esta definición es el uso de lo público al servicio de intereses personales o de grupo. En la categorización de SILVA, sin embargo, echo en falta la referencia a la configuración de lo público en clave de derechos humanos porque, de lo contrario, se le podría achacar que, en función de quien defina legalmente los intereses públicos o de quien tenga el poder, lo público tendiera epicúreamente hacia lo privado en un proceso simbiótico del que tenemos abundantes, y lamentables, casos en el mundo subdesarrollado, y no tan sudesarrollado, de nuestro tiempo. Es, eso sí, una buena descripción del fenómeno, pero no ataca frontalmente la cuestión de fondo de la corrupción que la hace especialmente censurable en todo tiempo y lugar.

\section{C.- UN FENÓMENO UNIVERSAL}

Siempre ha habido corrupción y siempre la habrá, puesto que mientras el hombre sea hombre, la tentación del abuso del poder estará presente y, en función del temple moral de quienes lo ejerzan, así será su extensión en nuestras sociedades. Pero en la historia de la humanidad es cierto que hay épocas en las que la corrupción ha estado más presente que en otras ${ }^{44}$. Ciertamente, el momento que vivimos en general no es de los más boyantes ${ }^{45}$.

Es un fenómeno universal ${ }^{46}$ que, sin embargo, parece que no ha sido muy estudiado desde el punto de vista histórico tal y como ha señalado el historiador FONTANA en un estudio titulado "Las reglas y el juego. Algunas reflexiones históricas sobre la corrupción". Sin embargo, parece que los momentos de decadencia, como el final del Imperio Romano, fueron especialmente proclives a

\footnotetext{
${ }^{44}$ Vid. R. DE LA CIERVA, Historias de la corrupción, Barcelona, 1992.

${ }^{45}$ Vid. J. VAN KALVEREN, Die historische Erscheinung der Korruption, in ihrem Zusammenhang mit der Staars und Gesellschafsstruktur bertrahtet; vietelfahrschrift Sozial u. Wirtschaftsgeschichte, 1957, pp. 294 y ss.

46 Sobre la corrupción en la etapa socialista en España, un buen resumen en J.A. ZARZALEJOS, Descripción del fenómeno de la corrupción.
}

REVISTA DO DIREITO UNISC, SANTA CRUZ DO SUL No $41 \mid$ p. 110 - 168| NOV - DEZ 2013 
la corrupción entendida, no tanto como el abandono o la inobservancia de las leyes, sino como la degradación de los representantes de la "res pública" que usaban la autoridad para beneficiarse personalmente, arruinando al pueblo, a los viejos grupos oligárquicos y al mismo emperador tal y como nos cuenta este académico. En realidad, la corrupción, como analiza este autor al analizar la situación política en la Francia y España de los siglos XVII y XVIII, parte siempre de la privatización del poder. $Y$ hoy, lógicamente, en un momento de honda y profunda crisis moral, también es así.

La corrupción también ha sido el resultado, comprobado a lo largo de la historia, de anteponer la fuerza al Derecho. La idea de que el poder debe estar al servicio de los derechos de los ciudadanos y que el poder tiene límites es una consecuencia de los principios básicos de la moralidad pública, de la Ética política ${ }^{47}$.

La idea de los límites frente al poder político se ha ido construyendo históricamente a través de un proceso conceptual que se inicia con la existencia de "grupos intermedios" que podían poner en relativo entredicho el poder del soberano. Más adelante surge la tesis de las funciones políticas limitadas con poderes y obligaciones impersonales y, finalmente, un sistema de orden público que establece los límites de la conducta ilegítima de quienes gobiernan.

Ciertamente, como señaló NAMIER, sin grupos intermedios significativos no podía haber límites para el poder de los monarcas absolutos ${ }^{48}$, porque entonces se pensaba que el Estado, por ejemplo THEOBALD, no era

\footnotetext{
${ }^{47}$ Vid. G. PECES-BARBA, La corrupción en las instituciones y en la sociedad civil, en Corrupción y Ética, Cuadernos de Teología Deusto, Bilbao, 1996, pp. 19 y ss.

${ }^{48}$ L. NAMIER, England in the age of the American Revolution, London, 1961, p. 4
}

REVISTA DO DIREITO UNISC, SANTA CRUZ DO SUL No 41|p. 110 - 168| NOV - DEZ 2013 
considerado como una realidad impersonal y jurídica, sino como la encarnación viviente de la herencia de los monarcas ${ }^{49}$.

Con la aparición, pues, de los cuerpos intermedios surge un relativo "pluralismo" que, en alguna medida, juega como poder moderador. Ahora bien, para que haya corrupción, es necesario que haya a quien corromper porque nadie corrompe cuando puede dominar. Cuando el poder se restrinje, entonces comienza la corrupción porque los grupos intermedios limitaban efectivamente el poder del soberano en favor de sus propios intereses ${ }^{50}$. En fin, los límites al poder del soberano, en estos primeros momentos, eran imprecisos y, en sentido estricto, todavía no puede hablarse, salvo como remoto precedente de funciones políticas modernas, de ideas concretas sobre el fenómeno de la corrupción.

La corrupción pública, que es la que examinamos en este trabajo, parte de la existencia de poderes públicos, de funciones públicas como concepto ya depurado técnicamente, que se traduce en elementos impersonales, por supuesto limitados y de los que se debe dar cuenta a los ciudadanos. Sin embargo, es sabido que al principio sólo podían acceder a los cargos públicos aquellos que estaban en los círculos próximos al poder, que las diferencias entre lo público y lo privado eran más bien poco claras y que las nociones de servicio público o de mérito y capacidad brillaban por su ausencia pues la política se concebía como ejercicio, mantenimiento y defensa del poder, y los fines políticos no iban mucho más allá del puro enriquecimiento.

\footnotetext{
${ }^{49}$ R. THEOBALD, Corruption, Development and Underdevelopment, Duke University, 1990, pp. 52-73.

${ }^{50}$ Vid. J. VAN KLAVERN, The concept of corruption, en HEIDENHEIMER, JOHNSTON, LEVINE, Op. cit., pp. 78-81.
}

REVISTA DO DIREITO UNISC, SANTA CRUZ DO SUL No 41|p. 110 - 168| NOV - DEZ 2013 
Pasaba el tiempo y las sociedades iban adquiriendo otro tamaño y una cierta complejidad. Por otra parte, las denominadas élites locales se multiplicaban y, por tanto, los conflictos entre ellas. Las guerras exigían más dinero y, por tanto, los soberanos tuvieron que empezar a contar con colaboradores a los que era, a veces, difícil controlar o supervisar. Por tanto, era necesario empezar a cobrar impuestos cuya recaudación se confiaba a particulares bien relacionados y con abundante patrimonio que se resarcían de sus "inversiones" reservándose parte de las rentas ${ }^{51}$. Se puso en marcha una operación, bien conocida, de venta de cargos. Poco a poco, hasta llegar al siglo XIX, en que se puede hablar, según SCOTT, de la idea moderna del Estado, aparece el ejercicio del poder como deber y desaparece la concepción de la actividad pública como propiedad privada.

Entonces surge lo que ROGOW y LASSWELL han denominado "sistema de orden público" 52 . Se trata de integrar los valores en las instituciones fundamentales del sistema y en todo el sistema político. En este sentido, la aproximación a la corrupción del profesor TARKOWSKI es el resultado de un proceso que consiste en la práctica de conductas abusivas en función de las referencias éticas que fundamentan el sistema de orden público. Por eso, hoy, pienso que siempre, la corrupción entraña claramente, amén de transformaciones impropias de lo público en privado, un evidente atentado al sentido del interés general, del interés público en sentido amplio, que se encuentran vinculado positivamente por el compromiso de los poderes públicos de facilitar, y promover, que todos los ciudadanos puedan ejercitar sus derechos fundamentales en un contexto de libertad solidaria.

\footnotetext{
${ }^{51}$ Vid. R.H. TAWNWY, Business and politics under James I: Lionel CRANFIELD as merchant and minister, Cambridge, 1958, pp. 91 y ss.

${ }^{52}$ A. ROGOW-H.D. LASSWELL, Power, corruption and rectitude, New Yersey, 1963, pp. 57 y ss.
} REVISTA DO DIREITO UNISC, SANTA CRUZ DO SUL No $41 \mid$ p. 110 - 168| NOV - DEZ 2013 
Ciertamente, la corrupción es un fenómeno universal ${ }^{53}$. Se da en todos los países aunque su alcance y desarrollo varían en el tiempo y espacio. Hoy se dispone de importantes estudios oficiales elaborados por los Gobiernos de Asia, África e Iberoamérica, fundamentalmente, que son de gran interés ${ }^{54} \mathrm{y}$ demuestran que existe corrupción, tanto en el mundo desarrollado como en los países en vías de desarrollo ${ }^{55}$. Estos estudios indican, además, que la corrupción existente se manifiesta bajo la forma de conculcaciones de procedimientos públicos para favorecer intereses personales bajo comisiones, sobornos para apoyos legislativos dirigidos a proyectos empresariales, uso de fondos públicos para fines personales, nepotismo, robo de caudales públicos, imposición de precios abusivos, cohechos, elaboración de proyectos ficticios, falseamiento de nóminas, fraudes en la recaudación de impuestos, facturas falsas, etc. Además, la corrupción, cuando se produce, se instala en casi todos los niveles de la gestión pública inclusive en la cúspide de los gobiernos bajo la constitución de una serie de privilegios especiales a favor de los miembros del ejecutivo. Las causas que nos presentan los documentos públicos suelen coincidir: presencia amplia del sector público en la gestión de la

\footnotetext{
53 "Ningún país es inmune a esta enfermedad de la corrupción y la gangrena se expande", se lamentaba Peter LOEUPRECHT, secretario general del Consejo de Europa en una conferencia de Ministros de Justicia celebrada en 1994 en malta. En este sentido, la Europa del Este, sin hábitos democráticos y con grandes problemas económicos y sociales se presenta cono un terreno propicio para la corrupción y el crimen: Así, en la citada cumbre de Malta, el Ministro polaco dijo que "el crimen en Europa ha cambiado. Tras suprimirse las restricciones para viajar e intercambiar bienes y dinero, y después del colapso del comunismo, tenemos ahora una realidad distinta, en la cual el crimen organizado y la corrupción pueden florecer". El Ministro ruso señaló que la democracia en Rusia está en peligro debido a la extensión de la corrupción. Pero en el occidente tampoco es que se estén proporcionando modelos de conducta exportables. En esta dirección, el Director General de Justicia inglés decía que si hay un comportamiento de corrupción entre hombres de negocios y políticos, por muchas leyes que se pongan, éstas no podrán cambiarlo; para ello tendría que haber una voluntad y un deseo de cambiar". Vid. También, J. MALEM, El fenómeno de la corrupción, en F. LAPORTA-S. ÁLVAREZ, Op. cit., pp. 71 y ss.

${ }^{54}$ Vid. los informes presentados al Seminario Internacional de las Naciones Unidas sobre corrupción en el Gobierno de 1989 y la ponencia de W. BENAISSA, Director de la División de Administración del Desarrollo de Naciones Unidas titulada "La corrupción y el contexto socio-cultural" presentada a la V Conferencia Internacional Anticorrupción, celebrada en los Países Bajos en marzo de 1992.

${ }^{55}$ Sobre la corrupción en EE.UU. vid. P. DE LEÓN, Public policy implications of sisemic political corruption, Corruption and Reform, Dordrecht, Kluwer Academic, Amsterdam, 1992, pp. 193 y ss. Es interesante también el estudio de C.J. DAVIES, Controling administrative corruption, Planning and Administration, The Hague, vol 14, $n^{\circ} 2$, 1987, sobre la corrupción en los gobiernos locales de Inglaterra y Gales.
}

REVISTA DO DIREITO UNISC, SANTA CRUZ DO SUL No $41 \mid$ p. $110-168 \mid$ NOV - DEZ 2013 
economía, reducción del libre mercado, debilitamiento de los sistemas de control, protagonismo creciente de los partidos políticos en la vida de la Administración pública, etc.

Los estudios sobre corrupción en los países en vías de desarrollo revelan hasta que punto este fenómeno está literalmente devorando la economía y la política de la mayoría de las naciones del Tercer Mundo ${ }^{56}$. Con frecuencia se encuentran referencias ${ }^{57}$ a que la burocracia se transforma, a veces incluso deliberadamente, en un sistema de dificultades y obstáculos frente a las legítimas aspiraciones y demandas de los ciudadanos y en una fuente de soluciones para problemas "artificiales" del cerrado mundo funcionarial. A veces, son también frecuentes los supuestos de conflictos de intereses, etc.

Una encuesta realizada en 1987 a cien funcionarios civiles de veinticinco agencias de Manila reveló, nos dice BENAISSA, que tanto el soborno como la corrupción eran las dos cuestiones que encabezaban la lista de asuntos de vergüenza nacional y la segunda de las cuestiones más graves a nivel nacional. Por otra parte, según consta en los archivos de un tribunal especial filipino de lucha contra el soborno, resulta que la malversación de caudales públicos era el supuesto más numeroso de sumarios contra funcionarios entre 1979 y 1989. En la India, según un estudio al que alude BENAISSA, la corrupción es mayor en función de la proximidad de los funcionarios con los ciudadanos. También se ha comprobado en más de una ocasión que la proliferación de normas y controles no sólo no despeja la corrupción, sino que, en no pocos casos, facilitan por paradójico que parezca, las prácticas corruptas. En la India también es frecuente que los funcionarios reciban dinero a cambio de facilitar concesiones de gas para las cocinas, las instalaciones eléctricas o telefónicas. En este supuesto, como señala BENAISSA, hay que tener en cuenta que la lentitud de la maquinaria administrativa a veces puede ayudar a

\footnotetext{
${ }^{56}$ Vid. R. KLITGAARD, Como controlar la corrupción, Incae, vol 4, nº 2, 1990, pp. 69 y ss.

${ }^{57}$ Vid. H. BENAISSA, loc. cit.
}

REVISTA DO DIREITO UNISC, SANTA CRUZ DO SUL No $41 \mid$ p. 110 - 168| NOV - DEZ 2013 
que penetre ente los propios funcionarios un clima de indiferencia y apatía en el que cuaja la corrupción. En definitiva, donde hay funcionarios motivados, conscientes de la importancia que tiene el servicio público y la promoción de los derechos de los ciudadanos, es difícil que pueda instalarse un ambiente de cierta degeneración y de falta de exigencia moral.

Otros estudios e informes revelan situaciones de corrupción. Así, LEE señaló en 1986 que a pesar de la honestidad y limpieza que en su opinión caracteriza a la función pública indonesa, también se dieron no pocos supuestos de corrupción debidos, en gran parte, a no haber sabido asumir en el sector público las consideraciones propias del sistema de mercado ${ }^{58}$. Otro estudio interesante es el elaborado por OUCHI sobre la conducta burocrática en Asia ${ }^{59}$. Para este autor, lo que es realmente preocupante en Japón no es la corrupción administrativa sino un ambiente de corrupción generalizada que trae su causa del capitalismo y del creciente protagonismo del sector público en la vida económica. El escándalo SAGAWA, en 1992, con más de ciento treinta políticos, es bien paradigmático de un marco en el que los grandes empresarios y los políticos tratan de dirigir la economía nacional hacia sus propios intereses a través de turbias relaciones con los altos funcionarios.

En Uganda, por ejemplo, la corrupción aparece en sus más variadas manifestaciones: sobornos, cohechos, malversación, uso de bienes públicos para fines personales, falsificación de facturas, pago de sueldos fantasma, nepotismo, comisiones, extorsiones. La causa, la existencia de poderes discrecionales cada vez

\footnotetext{
${ }^{58}$ Es el caso, por ejemplo, de la Junta de la Vivienda y Autoridad Portuaria.

${ }^{59}$ Un informe de la Fiscalía General del Estado en China asegura que la criminalidad de toda índole aumentó más del $60 \%$ en 1994 y que los casos de corrupción y soborno crecieron un 18\%. En este sentido, el Presidente del Tribunal Supremo de China señaló que los juicios por delitos económicos y de corrupción se incrementaron casi en un $70 \%$ en 1994 (El País, 13.III.1995, p. 6)
}

REVISTA DO DIREITO UNISC, SANTA CRUZ DO SUL № 41|p. 110 - 168| NOV - DEZ 2013 
más amplios. Como el control es tímido y mínima la responsabilidad, la parcialidad y el favoritismo, escribe BENAISSA, están a la orden del día ${ }^{60}$.

Los países hispanoamericanos tampoco han sido inmunes a la corrupción. El caso de México es bien claro. En este país la corrupción está tan generalizada que los ciudadanos deben sufrirla desde la cuna hasta la tumba. GOULD, en su estudio sobre México señala que el partido dominante recibe, en el marco del presupuesto público y bajo la rúbrica de gastos estatales, cerca del $20 \%$ de su importe. En Brasil se ha acuñado el concepto del "lato sensu" como uso del poder público para obtener ventajas para los funcionarios o amigos. La corrupción "strictu sensu" en Brasil es la tipificada en el Código Penal y se refiere a la percepción de beneficios económicos por el uso de las potestades públicas. En Argentina, según un estudio del que de cuenta BENAISSA, se dan formas de corrupción no pecuniarias como pueden ser el nepotismo y el uso indebido de bienes materiales ${ }^{61}$.

El problema, pues, es el de la corrupción institucionalizada. Porque corrupción siempre habrá, pero lo preocupante es que se instale en la vida privada y pública y constituya una cuestión normal. En estos casos, la corrupción se tolera incluso socialmente $y$, como ha señalado CAIDEN, lógicamente molestan las referencias a la Ética del servicio público porque el modelo de conducta que se practica es bien otro. Hasta tal punto es grave la situación que hay quienes piensan, y escriben, que la corrupción general, en los países menos desarrollados, atrae la inversión extranjera y refuerza el sector privado, aumenta la integración de las

\footnotetext{
${ }^{60}$ R.B. CHARLICK, en Corruption in political transition: a governance perspective, corruption and Reform, Dordrecht, vol. 7, nº 3, Kuwer Academic, Amsterdam, 1992, pp. 177 y ss, señala que la corrupción en África representa un síntoma de una pobre gestión de gobierno y de que la sociedad no puede manejar eficazmente sus recursos para satisfacer el interés general.

${ }^{61}$ Vid. además, W. LITTLE, Political corruption in Latin America, Corruption and Reform, Dordrecht, vol. 7, ${ }^{\circ}$ 1, KLUWER Academic, Amsterdam 1992, pp. 41 y ss y S.D. MORRIS, Corruption and the Mexican political system, Corruption and Reform..., cit, pp. 3 y ss.
}

REVISTA DO DIREITO UNISC, SANTA CRUZ DO SUL $N^{\circ} 41 \mid$ p. 110 - 168|NOV - DEZ 2013 
minorías y fomenta la modernización política; es una alternativa preferible a la violencia y garantiza la estabilidad social. Sin embargo, aunque formal y externamente ello pueda ser así, debo señalar que los hábitos de corrupción socavan la democracia, producen desigualdad e impiden el pleno desarrollo personal del conjunto de la población, por lo que, a pesar de los pesares, en este tipo de países es muy conveniente, aunque sea en perjuicio de la situación económica, que se pongan en marcha programas culturales y educativos de Ética en los que se explique la importancia de los derechos humanos y la función instrumental de la burocracia. Porque la Economía está al servicio del hombre y la Administración también y todo lo demás, por muy positivo y "económico" que resulte, no hace más que contribuir a la degradación moral de la sociedad y a fomentar la desigualdad social. Sin embargo, hay que admitir que para cambiar estas situaciones hay que ir lentamente transformando actitudes y talantes.

Ciertamente, las situaciones de corrupción general se producen por una evidente falta de conciencia de servicio público al entender la función pública como una manera de servir los propios intereses personales, ya sean inmateriales o pecuniarios. También tiene mucho que ver la situación de distanciamiento entre gobernantes y ciudadanos $y$, en el fondo, como reconoce CAIDEN, la ausencia de virtudes cívicas y morales porque las personas con sólidos principios éticos y morales son difíciles de corromper pues tienen bien claro cual es el fin de su trabajo público: servir a los ciudadanos y procurar fomentar el libre ejercicio de los derechos humanos. Estos ciudadanos, dice CAIDEN, no temen sacrificarse porque están convencidos del sentido de su tarea y tienen la fuerza suficiente parta resistir, y vencer, estas complejas y nada fáciles tentaciones del egoísmo y la arrogancia que, por cierto, tanto han proliferado en el ambiente democrático de nuestro tiempo. 
A finales de diciembre de 1992, el 17 de diciembre, el profesor Yves MENY, participó en la Universidad de "La Sapienza" en un seminario sobre la corrupción en Francia y en Italia ${ }^{62}$. Para MENY la corrupción ha aumentado en los últimos tiempos por los problemas de financiación de los partidos políticos y por el aumento de la discrecionalidad aparejado a la reciente reforma descentralizadora de Francia. Después de comentar la célebre distinción de HEIDENHEIMER, el profesor MENY alerta contra el peligro de la instauración de una cultura de la corrupción que parte de tolerar la llamada "corrupción blanca", para fines personales, y la "gris", para el partido o el grupo al que se pertenece. Además, la fragilidad de las leyes de incompatibilidades, la proliferación de normas y normas, la falta de compromiso personal, y la prevalencia de la eficacia en la Administración pública, son factores que, en opinión de MENY, facilitan esta temible cultura de la corrupción. Los ámbitos más propicios para la corrupción serán aquellos en los que prima la discrecionalidad: planeamiento urbanístico, concesiones de servicios públicos, etc ${ }^{63}$.

\section{D.- ALGUNAS CAUSAS}

La corrupción es desencadenada por factores varios. Entre ellos se puede citar el relajamiento de los principios morales, que da lugar a una proliferación del mal ejemplo. Ahora bien, si hubiera que elegir una causa principal pienso que la unanimidad no sería difícil: el deseo inmoderado de riqueza, poder y notoriedad. Es, por tanto, la actitud ante los bienes materiales e inmateriales el fundamento de una sociedad sana o de una corrupta. Es triste, pero no parece desatinada esa frase de USLAR PIETRI cuando señala que "tener o no tener dinero marca la más fundamental diferencia entre los hombres". Es una pena, pero no se puede dejar de reconocer que en los tiempos que corren todo se mide en términos

\footnotetext{
${ }^{62}$ Vid. Rivista trimestrale di Diritto Pubblico, $\mathrm{n}^{\circ} 3,1993$, pp. 940 y ss.

${ }^{63}$ Vid. A. NIETO, Op. cit., pp. 45 y ss.
}

REVISTA DO DIREITO UNISC, SANTA CRUZ DO SUL No $41 \mid$ p. 110 - 168| NOV - DEZ 2013 
económicos y se ha ido diluyendo la importancia de los valores de la persona y su aspiración a realizarse como tal en un mundo en paz.

El poder del dinero es casi absoluto, Por qué ? Porque, sencillamente, estamos en un momento de crisis moral, de cierta degradación de los valores humanos y no hay capacidad de resistencia. Como escribió el poeta BAQUILIDES "el amor al oro alcanza muchas veces la victoria cuando combate con una virtud demasiado débil". Y hoy, se practican poco las virtudes. El dinero ha provocado una profunda transformación: cambia el carácter, el modo de ser, la idea misma de la personalidad y la vida se convierte en una sucesión de distintas oportunidades.

Al final, la riqueza, como escribía Anatole FRANCE "es el fin único de la existencia" y da lugar a esa peligrosa desvinculación entre trabajo y riqueza que tantos estragos ha hecho y que tan nociva es para la vida de los pueblos. Sobre todo porque se busca el dinero y la riqueza a cualquier precio y en el menor plazo de tiempo posible. Y lo peor: se huye del esfuerzo o se ridiculiza hasta cierto punto todo lo que sea trabajo continuo, constante y esforzado. Como escribe USLAR PIETRI, el poder ser rico sin trabajar, el creer que se puede disfrutar permanentemente de abundancia de dinero sin necesidad de hacer ningún esfuerzo para ganarlo, esta situación es un auténtico cáncer capaz de minar los cimientos morales de cualquier sociedad y, además, constituye un campo bien abonado para la corrupción. Pero, con todo, lo más grave es que este tipo de fenómenos se instala en todas las capas sociales y tiende a perpetuarse porque, como dirá JUVENAL, "el amor a las riquezas crece conforme el dinero y quien menos tiene, menos desea" o EURÍPIDES: "el oro aleja a los mortales de la moderación y les arrastra a los excesos de un injusto poder". 
Por todo ello, el acento se pone en las cosas que se tienen, y no en lo que se es. En un ambiente o clima de corrupción se abandona lo que no reporte ventajas económicas. Se olvida lamentablemente el sentido instrumental del dinero y de las riquezas, y se convierten en un ídolo. Por eso la Ética es importante, por eso hay que apelar a la necesidad de que lo fundamental es la persona y su libre desarrollo, porque en un horizonte de creciente materialismo se pierde perspectiva y la existencia se convierte en una vertiginosa carrera hacia la acumulación de toda clase de bienes materiales al pensar que el dinero lo suple todo y lo compra "todo" porque "todo" tiene precio sin excluir a los poderes públicos. En una situación de esta naturaleza, lo más triste, insisto, es que se pierde la referencia humana porque cuanto más posee el hombre, sentenciará GRAF, menos se posee.

Este ambiente procede, me parece, de ese capitalismo salvaje en que, nos guste 0 no, estamos instalados desde hace tiempo. Lo ha descrito acertadamente PECES-BARBA: "la necesidad de acrecentar y multiplicar el capital ha ido generando e impulsando mecanismos de exclusión de competidores, para lo cual ha sido necesario contar con el poder político, que debía tomar determinadas decisiones jurídicas para favorecer esas ventajas"64. En este contexto, nos sigue diciendo el ex Rector, ya fallecido, de la Universidad Carlos III "tanto desde los corruptores como de los corruptos el móvil de su conducta es el cálculo de utilidad para maximizar los beneficios, llegando tan lejos como es posible con el mínimo riesgo". La causa de ese capitalismo exacerbado es un individualismo radical que ha eliminado toda referencia al interés general, al bien común, para promover toda suerte de proyectos de vida de corte nítidamente egoísta a partir de los grandes aliados: el dinero y el poder ${ }^{65}$.

\footnotetext{
${ }_{65}^{64}$ ABC, 30.X.1994, p. 3

${ }^{65}$ Las razones económicas han sido aludidas como causas de la corrupción: M. SOBRADO, Privatización de la política y política de privatización, Ciencias Sociales, no 183, 1999, pp. 139 y ss: Z. BREI, A corrupçao: causas, conseqüencias e solucoes para o problema, RAP (Brasil), $n^{\circ} 30,1996$, pp. 103 y ss. o A. DOIG, The

REVISTA DO DIREITO UNISC, SANTA CRUZ DO SUL $N^{\circ} 41 \mid$ p. 110 - 168|NOV - DEZ 2013
} 
Desde otro punto de vista, más de teoría administrativa, se puede decir que ese pulso al que hemos asistido entre eficacia y legalidad se ha saldado con una pretendida búsqueda de resultados a toda costa que muchas veces ha traído consigo una ausencia de controles que ha permitido a los más desaprensivos manejar los fondos públicos a su antojo. Este es un tema capital: ni mucho menos pretendo que se vuelva a un rígido sistema de controles pensado para una Administración "bajo sospecha". Pero lo ocurrido en España en el pasado, que ahora tristemente ha resucitado, aconseja buscar nuevas fórmulas de control racionales que de verdad permitan gestionar con eficacia en un contexto de legalidad y de servicio a los ciudadanos. En esos años, década de los ochenta del siglo pasado, cuanto más se insistía la necesidad de agilidad, de flexibilidad o de eficiencia en el funcionamiento administrativo, se olvidaba algo muy importante: que la eficacia si no se integra en la legalidad y en el marco propio de la actividad administrativa, no sirve.

privatisation of the property services Agency: Ask and vulnerability in contrat-Delated fraud and corruption, Public Policy and Administration, vol. 12, n 3, 1997, pp. 6 y ss.

REVISTA DO DIREITO UNISC, SANTA CRUZ DO SUL $N^{\circ} 41 \mid$ p. $110-168 \mid$ NOV - DEZ 2013 
Cuando se trata de controles, hay que ser conscientes que también puede haber, como ha estudiado el profesor OUTRIVE, controles generadores de corrupción ${ }^{66}$. En concreto, este académico se refiere, sobre todo, al famoso informe DANKERT, relativo al fraude existente en la Unión Europea que, en buena parte, se produce porque, entre otras razones, quienes conceden las subvenciones y quienes las controlan proceden en algunos casos de los mismos ambientes o círculos que los propios beneficiarios de esas ayudas ${ }^{67}$.

Otra de las causas que más se han tratado como causas de la corrupción es el crecimiento de la discrecionalidad administrativa. Efectivamente, como han señalado FISHER y ZINKE, en el sistema burocrático se han identificado una serie de barreras que dificultan el cumplimiento ético en las organizaciones públicas. Es decir, es muy difícil definir una zona de la actividad en la que haya suficiente discrecionalidad auténtica para las decisiones éticas ${ }^{68}$. La discrecionalidad de los altos funcionarios ha sido siempre, nos recuerda DOBBEL, un tema de especial interés en las sociedades democráticas ya que su uso puede aparecer tendencialmente, según las épocas, desnaturalizado en forma de abuso o de usurpación. La cuestión está en saber cómo utilizar estos poderes al servicio del interés general en un contexto del bien común ${ }^{69}$. Y, con independencia de las técnicas jurídicas, bien conocidas, de control de la discrecionalidad, lo que aquí interesa destacar es que, como dice DOBBEL, la principal arma contra el ejercicio abusivo de la discrecionalidad es la integridad personal ${ }^{70}$. Es más, como ha

\footnotetext{
${ }^{66}$ L. OUTRIVE, La Administración como amplificadora de la corrupción, V Conferencia Internacional Anticorrupción, Amsterdam, 1992.

67 Vid. M. GONZÁLEZ DE ASÍS, La corrupción internacional. Un examen empírico de sus causas, GAPP, $\mathrm{n}^{\mathrm{o}} 10,1997$, pp. 3 y ss.

${ }^{68}$ F. FISHER-R.ZINKE, Public Administration... loc. cit., pp. 841-854

${ }^{69}$ P. DOBEL, Integrity... loc. cit., pp. 354-366

${ }^{70}$ Ibidem
}

REVISTA DO DIREITO UNISC, SANTA CRUZ DO SUL No $41 \mid$ p. 110 - 168| NOV - DEZ 2013 
estudiado Charles FOX, desde un punto de vista fenomenológico, existe un "espacio ético" en el que los funcionarios deben operar las potestades discrecionales ${ }^{71}$.

Las leyes, la legislación, también tienen mucho que ver con la corrupción. Porque vivimos en un mundo en que hay demasiadas normas, en el que la maraña jurídica es tan densa que es muy difícil su cumplimiento, cuando no su conocimiento. Pero, en todo caso, es lógico pensar que la legislación deba ser un remedio contra lo injusto en la medida que la ley, dice el profesor de Lovaina OUTRIVE, debe ser una estructura que controle los intereses privados en nombre del bien común ${ }^{72}$. Sin embargo, cuando la legislación se contempla desde la perspectiva de las relaciones de poder, nos encontramos con la existencia de grupos de presión que tratan a toda costa de condicionar el procedimiento legislativo para imponer sus puntos de vista. Evidentemente, así considerada la ley, no es nada raro que pueda llegar a convertirse en un factor de corrupción como manifestación o expresión de relaciones de poder desiguales ${ }^{73}$.

OUTRIVE, que ha estudiado la corrupción en el marco de la Unión Europea, señala que la complejidad y falta de claridad de las normas comunitarias es una de la causas de la corrupción. Es más, cuantas más Leyes y Reglamentos, más infracciones pueden producirse ${ }^{74}$. Por ejemplo, el elenco de subvenciones 0 ayudas a la exportación consta de más de mil quinientas clasificaciones de productos agrícolas que incluyen cerca de cuatrocientas para productos lácteos y alrededor de ochocientas, por ejemplo, para la carne de buey. A finales de 1987, el sistema de codificación de la tarifa aduanera comunitaria contenía más de mil quinientos códigos de productos agrícolas, cifra que se incrementó en dos mil

\footnotetext{
${ }^{71}$ C. FOX, Free to choose, free to win, free to lose: the phenomenology of ethical space, International Journal of Public Administration, 1989, pp. 913-930.

${ }^{72}$ L. OUTRIVE, loc. cit. Además, vid. N. PASSAS-D. NELKEL, The fight against fraud in the European Community: cacophony rather than harmony, corruption and Reform, cit., pp. 237 y ss.

${ }^{73}$ L. OUTRIVE, Loc. cit.

${ }^{74}$ L. OUTRIVE, Loc. cit.
} 
quinientos códigos como consecuencia de la tarifa integrada basada en un sistema armonizado $^{75}$. En fin, el informe DANKERT, ciertamente crítico, señala que el Consejo de Ministros comunitario, como es bien sabido, no está obligado a dar cuenta de sus actos ni al Parlamento Europeo ni al de los Estados Miembros y, que, por lo tanto, el denominado "legislador" puede legislar de forma que pueden producirse fraudes.

\section{E.- CORRUPCIÓN Y ECONOMÍA}

Cuanta más intervención pública, ordinariamente, por obvias razones, más posibilidades de corrupción. Cuanta mayor presencia pública se produzca en la vida económica, mayor índice de corrupción. Desde luego que estas sentencias son resultado de lo que realmente ha pasado. Es verdad que el poder puede corromper y es verdad, ciertamente, que si no se tienen claras las exigencias de la Ética del servicio público la corrupción puede ser más fácil.

Hoy, que ya ha caído el comunismo, nos encontramos ante un capitalismo que, como ha señalado VELARDE FUERTES, tiene como centro la búsqueda del beneficio, pero sin las condiciones que impone el teorema de la mano invisible de Adam SMITH. Se trata de ese capitalismo duro en el que cabe todo siempre que provoque beneficios, ya sea a corto o a largo plazo. En este supuesto, es necesario que se instaure un auténtico mercado libre en un marco de imprescindible regulación porque, como sentencia el profesor VELARDE, intervencionismo con corporativismo más búsqueda desenfrenada de beneficios es igual a corrupción.

\footnotetext{
${ }^{75}$ Vid. N. PASSAS, Frauds affecting the budget of the European Community, 1991, (Xerocopia), pp. 105-106. Vid. también, H. NILSSON, El futuro de la corrupción en Europa, V Congreso Internacional Anticorrupción, Amsterdam, 1992, Manuscrito.
}

REVISTA DO DIREITO UNISC, SANTA CRUZ DO SUL No 41|p. 110 - 168| NOV - DEZ 2013 
La corrupción en el ámbito económico equivale, como han señalado PORTELA y ZAMORANO, a la venta o intercambio de favores por parte de funcionarios o políticos a determinadas personas del sector privado y del propio sector público ${ }^{76}$. Ciertamente, las prácticas mercantiles del sector privado, que crean determinados estilos o formas de actuación, se diferencian de los planteamientos de los administradores públicos en que éstos siempre tienen elementos objetivos para tomar decisiones de coste-beneficio en el marco de la ley de Contratos del Estado. Sin embargo, la cuestión es que el sector público aparece frecuentemente en situación de monopolio y los funcionarios o políticos que deciden lo hacen en un contexto de discrecionalidad en el que el suministrador puede obtener pedidos tan sólo porque hace favores o da dinero a quien puede decidir.

Los perjuicios que ocasiona la corrupción en el ámbito económico son incontables. El más grave es la conculcación de los principios constitucionales de publicidad y concurrencia. Pero hay más datos negativos. Puede producirse la pérdida del beneficio potencial derivado del hecho de que determinada actividad sea concedida a la empresa menos eficiente. PORTELA y ZAMORANO, a quienes seguimos en este punto, hacen referencia a que la corrupción ocasiona también la reducción de los usuarios de los servicios a causa del aumento de los costes debidos a los sobornos. También se produce un evidente perjuicio a los consumidores de los servicios cuando las concesiones son realizadas a organizaciones no cualificadas.

Cuando el Estado crece y crece sin parar, tienden a aumentar toda suerte de grupos destinados a obtener ganancias con cargo al presupuesto público. Aunque duela reconocerlo, sabemos que es un hecho bien cierto y que se repite cíclicamente con el paso de los años. Evidentemente, con un Estado más reducido,

\footnotetext{
${ }^{76}$ En general, vid. S. ROSE-ACKERMAN, corruption: a study in Political Economy, New York, 1978.

REVISTA DO DIREITO UNISC, SANTA CRUZ DO SUL $N^{\circ} 41 \mid$ p. 110 - 168| NOV - DEZ 2013
} 
estos grupos de presión carecerían de estímulo porque los poderes públicos apenas pueden promocionar ventajas especiales.

Ciertamente, los grupos de presión que surgen al socaire del presupuesto y que trafican con él, se han convertido, por sorprendente que parezca, dice BERNALDO DE QUIRÓS, en elementos fundamentales para la toma de decisiones en el sistema democrático. Venden votos a cambio de favores administrativos y el Estado se ha convertido en una amalgama putrefacta de intereses particulares que anula cualquier intento de robustecer una sociedad civil que cada vez queda más relegada. El final del proceso, escribe BERNALDO DE QUIRÓS, es la configuración del Estado como un enorme botín, y sus funciones como una oficina de intercambio de favores y privilegios. Quizá sea un poco exagerado este panorama, pero desde luego, en algún caso es bien patente y demuestra hasta que punto el intervencionismo es causa, también, de la corrupción en el ámbito económico.

El aumento de la discrecionalidad debe ir acompañado de un crecimiento de la ejemplaridad ética de políticos y funcionarios porque, de lo contrario, la corrupción está servida y, lo que es más grave, está facilitada o promovida desde el mismo poder público.

En el marco del intervencionismo es más fácil la corrupción ${ }^{77}$. Si, pero, en mi opinión, el problema fundamental no es tanto la intervención como la preparación y calidad ética de funcionarios y políticos. Hay momentos en los que puede ser necesaria una mayor presencia de los poderes públicos en la vida económica, fenómeno que en si mismo, no se puede calificar de malo o corruptor. Más importante es el control de la discrecionalidad y profundizar en el buen uso de

\footnotetext{
${ }^{77}$ Vid. los interesantes capítulos del libro de ROSE ACKERMAN citado: "Monopolistic bureaucracy", "bureaucratic structure and corruption" y "bureaucratic corruption and the legislative process".

REVISTA DO DIREITO UNISC, SANTA CRUZ DO SUL No $41 \mid$ p. $110-168 \mid$ NOV - DEZ 2013
} 
los poderes al servicio de la colectividad. Por eso, no puedo compartir la tesis de que los hombres públicos son un colectivo de alto riesgo. Puede que lo sean en determinados momentos, pero establecer principios generales es arriesgado. Como lo es, también, apuntar que la causa básica será analizar si los mecanismos de toma de decisiones constituyen un freno suficiente a las inclinaciones perversas de los hombres públicos. Ciertamente, hay que limitar la discrecionalidad pero no anularla. Habrá que buscar personas con vocación de servicio. Esto es más importante.

En el marco de la economía no se puede olvidar que, como señalara certeramente OFFE, los sistemas de toma de decisiones no responden, ni al modelo de legitimación democrática, ni al perfil weberiano del funcionario público. Es más, no se puede negar que las decisiones políticas muchas veces se producen en informales procesos de negociación entre representantes de sectores estratégicos públicos y privados de forma que los que participan en este tipo de relaciones tienen todos los motivos para mantener su "interesante" intercambio de propuestas, información y amenazas. En este contexto, no puede extrañar a nadie que cuajen fenómenos de "tráficos de influencias" con el fin de anticiparse en el conocimiento, preparación o adopción de determinadas actuaciones con la finalidad de obtener algún tipo de beneficio personal.

Hoy, en el ámbito de las finanzas, hay que reconocer que el control de los accionistas brilla por su ausencia con lo que los directivos han ido aumentando sus ventajas a través del uso de activos (coches, aviones...) o retribuciones especiales (gastos de representación). El resultado ha sido la instalación de una nueva clase social llamada "beautiful people" o "nuevos ricos" que han traído consigo distintos supuestos de compra de empresas o "tiburoneo" empresarial que traen su causa de la utilización de dinero prestado contra la garantía de los activos 
de la empresa para adquirir la mayoría de las acciones de esa masa pasiva de accionistas $^{78}$. Al final, hay que vender las partes más rentables de las empresas y, después, cerrarlas. Ahora, eso sí, en todo este proceso se amasan grandes fortunas como consecuencia de informes o dictámenes que, al final, no son más que informaciones privilegiadas por escrito. Lo peor es que este ambiente, y sobre todo sus protagonistas, han sido considerados dignos de imitación en el mundo del sector público con los consiguientes desaguisados y escándalos que no hacen más que aumentar en la España de hoy.

${ }^{78}$ U. NIETO DE ALBA, Op. cit., p. 40

REVISTA DO DIREITO UNISC, SANTA CRUZ DO SUL No $41 \mid$ p. $110-168 \mid$ NOV - DEZ 2013 
Los procesos de privatizaciones y reprivatizaciones son también campos bien abonados para la corrupción. Ya veremos, si es que algún día se conoce, qué pasó con la reprivatización de RUMASA en España. En estos casos, sin un procedimiento transparente y reglado, las enajenaciones al sector privado bien pueden consistir en el pago a grupos y "lobbies" que merezcan recompensa en función de su colaboración con los dirigentes del partido o por su participación en determinadas operaciones de intercambio o compraventa de favores. Porque ¿cómo se puede justificar la venta de una empresa al sector privado por precios irrisorios?

También el campo de la generación de plusvalías es plato de gusto para los expertos en corrupción. Hoy, no se puede negar, las obras públicas producen claras y cuantiosas plusvalías a los propietarios de los terrenos próximos a dichas obras. Pero, como muy bien señala el profesor NIETO DE ALBA, es lógico pensar que parte de esos beneficios deben redundar en la comunidad aunque la solución no debe venir por la participación del Estado como un especulador más, sino a través de la adopción de medidas que supongan contrapesos institucionales que eviten el ocultamiento de malas gestiones e impidan especulaciones por parte de los gestores públicos que puedan ser fuente de información privilegiada, tráfico de influencias o conductas corruptas ${ }^{79}$.

Es verdad que la llamada "cultura del pelotazo" es más frecuente en sistemas intervencionistas en los que los cargos públicos disponen de toda suerte de prebendas y pueden comprar y vender continuamente favores de tipo político y económico. En realidad, cuanto mayor sea la libertad de mercado, la transparencia y la competencia, menor será la corrupción. Por eso, es necesario reducir el sector público empresarial a sus justos límites, recuperar el control eficaz sobre la adjudicación de caudales públicos de acuerdo con los principios constitucionales y

\footnotetext{
${ }^{79}$ U. NIETO DE ALBA, Op. cit, p. 42.
}

REVISTA DO DIREITO UNISC, SANTA CRUZ DO SUL No 41|p. 110 - 168| NOV - DEZ 2013 
buscar un sistema de financiación de los partidos políticos que no asocie su presencia "necesaria" en los procesos de contratación pública.

\section{F.- $\quad$ ALGUNAS MANIFESTACIONES}

La corrupción pública implica, como ya hemos señalado, un ejercicio impropio de las potestades públicas. Por tanto, tantas veces como se produzca esta desnaturalización de los poderes públicos estaremos ante tantas modalidades de corrupción. Por eso, establecer una tipología de la corrupción es una tarea francamente difícil, sobre todo si se pretende realizarla con pretensiones de validez universal.

Quizá lo más interesante sea señalar algunas de las manifestaciones que, en estos tiempos, son más frecuentes ${ }^{80}$. Así, por ejemplo, en el ámbito económico se producen frecuentemente ofrecimientos de dinero con el fin de sobornar para obtener algún beneficio personal o de grupo. En estos casos se ofrece dinero, bien en metálico o en cuentas, donativos, ayudas a partidos políticos, regalos, servicios gratuitos, viajes pagados, encargos profesionales, participaciones accionariales, puestos en Consejos de Administración, colocación de amigos o de familiares. $\mathrm{Y}$, lo que se otorga, son, entre otras cosas, permisos, concesiones, información privilegiada; nombramientos, exenciones, subvenciones, adjudicaciones, recomendaciones, etc.

${ }^{80}$ Vid. A. NIETO, Op. cit. Pp. 112 y ss.

REVISTA DO DIREITO UNISC, SANTA CRUZ DO SUL No $41 \mid$ p. 110 - 168| NOV - DEZ 2013 
Hoy, desgraciadamente, una sospecha generalizada de corrupción se extiende sobre la actividad pública. Desde este punto de vista, el profesor SOTELO distinguía no hace mucho tres tipos de corrupciones ${ }^{81}$.

El primero se refiere a la corrupción individual. Se refiere al político o funcionario que aprovecha su cargo para su propio beneficio. $\mathrm{Y}$, como dice SOTELO, es una modalidad de corrupción que es, y seguirá siendo, una tentación perpetua $^{82}$.Un segundo tipo de corrupción, según SOTELO, es la patrimonial y es propia de sociedades económicas y políticamente subdesarrolladas en las que el poder político, sin control democrático, maneja los fondos públicos como un patrimonio personal. Y, finalmente, un tener tipo de corrupción, muy extendida en el área europea, y que amenaza, escribe el profesor SOTELO, con vaciar de sentido las instituciones democráticas, es la corrupción que trae consigo la financiación de los partidos políticos.

En este tiempo la corrupción ha aumentado considerablemente en casi todas las partes de este mundo. El caso italiano es probablemente uno de los más tristes y ha demostrado que, casi siempre, detrás del funcionario o político corrupto hay una fuerza política a la que debe el nombramiento y que lo ha colocado con la función de dejarse corromper y repartir el botín con el partido. El caso italiano demuestra, como escribía SPADOLINI en $1993^{83}$, que la cuestión moral es la primera y más importante de todas las cuestiones políticas ya que puede dar lugar al distanciamiento de los ciudadanos respecto a la política.

\footnotetext{
${ }^{81}$ Vid. I. SOTELO, Salirse por la tangente, El País, 21.IV.1993, pp. 15-16.

${ }^{82}$ Sobre el cohecho, Vid. M.J. RODRÍGUEZ PUERTA, El delito de cohecho, Madrid, 1998.

${ }^{83}$ G. SPADOLINI, Los males de Italia: la corrupción y el resto, ABC, 5.XII.1993, Análisis V.
}

REVISTA DO DIREITO UNISC, SANTA CRUZ DO SUL No $41 \mid$ p. 110 - 168| NOV - DEZ 2013 
Pero el caso italiano no es único. También son bien conocidos los casos de corrupción en Japón, donde el partido liberal perdió la mayoría absoluta que tenía desde hace cuarenta años. China, Iberoamérica, Alemania, Francia, España... tampoco se quedan atrás y engrosan la lista de países aquejados por este mal de la corrupción.

La especulación, como sabemos, es en esencia la compra de un bien con la finalidad de venderlo obteniendo beneficios. En principio, pues, no se trata de algo "per se" malo a no ser que se obtengan beneficios "desproporcionados" o que se produzca la especulación en un contexto de información privilegiada. En este último caso, se produce un robo porque se usa de un bien de otro para beneficio personal. Es el caso de adquisiciones de terrenos en que una de las partes sabe que serán recalificados, con lo que se producirá un evidente incremento de su valor. El fin no justifica los medios.

Curiosamente, sin embargo, en el contexto internacional parece poco menos que inevitable que, so capa de perder algún contrato que se juzga fundamental, se produzcan comisiones. Es un tema, el de las comisiones internacionales, bien delicado. Para tratar de eliminar estas prácticas irregulares, una Comisión de la Organización para la Cooperación y el Desarrollo Económico (OCDE) está trabajando sobre un proyecto de Código de Conducta en el Comercio Internacional. Es una cuestión delicada porque hay que determinar cuando una comisión es ilegal y cuando es correcta. Pues bien, el grupo de la OCDE propone, para estos casos, un criterio muy sencillo: la transparencia, porque lo ilegal se oculta por principio. Por ello, las empresas deberían incluir en algún concepto bien definido de su contabilidad el pago de comisiones comerciales consignando en un anexo el servicio que remuneran y la identificación del beneficiario. 
En el mundo de la empresa, y también de la vida pública, se producen a veces esos terribles sucesos conocidos con el nombre de sobornos y extorsiones. Fenómenos que ciertamente no son novedosos ya que los pagos expúreos en los negocios o en las contrataciones públicas han sido una de las prácticas corruptas más practicadas.

En un soborno, señala el profesor MELÉ, alguien ofrece dinero o alguna otra dádiva a una persona o a un equipo vinculado a alguna empresa o a la Administración pública, para obtener alguna suerte de beneficio. ¿ Para qué se soborna ? Pues para obtener sentencias o arbitrajes injustos, para el encubrimiento de delitos, para conseguir la adjudicación de contratos o el logro de subvenciones, así como exenciones, permisos, licencias... Si interviene algún funcionario público, se llama cohecho ${ }^{84}$.

Las extorsiones, como señala también el profesor MELÉ, parten de quien tiene el poder de decisión o puede ejercer influencia sobre quien decide. El extorsionador exige dinero a alguna otra dádiva a alguien, sin que tenga ningún derecho a ello, a cambio de otorgar algún provecho o, simplemente, pide alguna recompensa por hacer algo a lo que está obligado por razón del cargo bajo amenaza de dilatar desmesuradamente su gestión con prejuicio del extorsionado.

Una cuestión también delicada es la de los regalos y las atenciones comerciales porque, en ocasiones, bien pueden considerarse sobornos si es que son desmesurados o desproporcionados, En general, como señala atinadamente Domenech MELÉ, es mejor no aceptar ninguna atención que aparezca desmesurada y, en todo caso, las atenciones recibidas no deben obstaculizar la

\footnotetext{
${ }^{84}$ Sobre el soborno en el ámbito público, vid. V. BERKMAN, Bureaucratic and bribery: a conceptual framework, International Journal of Public Administration: vol 15, $\mathrm{n}^{\circ}$ 6, 1992, pp. 1345 y ss. Sobre el soborno en Alemania, vid. El País, 24.II.1995, p. 8. Recientemente, S. ÁLVAREZ, Reflexiones sobre la calificación moral del soborno, en F. LAPORTA-S. ÁLVAREZ, Op. cit. Op. 91 y ss.
}

REVISTA DO DIREITO UNISC, SANTA CRUZ DO SUL № 41|p. 110 - 168| NOV - DEZ 2013 
libertad e independencia necesaria para elegir lo que se estime mejor para la empresa a la que se representa.

Quizás hoy la forma de corrupción más extendida sea el uso ilícito de información o también llamado tráfico de "información privilegiada". Se trata, en estos supuestos, como ha señalado el profesor ARGANDOÑA, de aquella información que tiene una persona en situación de confidencialidad o lealtad para con una empresa, que puede producir beneficios extraordinarios al alterar el valor de las acciones o de otros activos financieros de la empresa, y que se usa en beneficio del que posee la información en la Administración pública. Entonces nos encontraríamos en un supuesto de información privilegiada pública. La conducta anti-ética surge porque el que tiene la información privilegiada la utiliza en su beneficio, falseando las reglas de la publicidad y concurrencia del mercado. Además, el uso abusivo de información privilegiada genera situaciones de notoria injusticia porque priva a alguien de algo a lo que tiene derecho ${ }^{85}$.

La información privilegiada, dice ARGANDOÑA, dificulta que todos tengan derecho a la misma información y que todos tengan acceso a la misma información. En el mundo de la Administración pública es especialmente grave pues la publicidad y la concurrencia en la contratación pública constituyen principios constitucionales. Es más, como ha señalado el profesor Salvador $\mathrm{CODERCH}$, el concejal que se entera de los planes sobre el nuevo trazado de una carretera $y$, antes de que se haga público, se dedica frenéticamente a comprar solares a sus convecinos para luego especular con ellos, hace ciertamente un buen negocio, pero lo hace a costa de sus vecinos y sin mérito alguno por su parte: lo que él gana, lo pierden los demás. Por eso, es realmente aborrecible el tráfico de "insiders", recalca $\mathrm{CODERCH}$, montado sobre una información privilegiada a la que se tiene acceso por razón del cargo que ocupa. Es claro que este tipo de actuaciones es censurable:

\footnotetext{
${ }^{85}$ P. MELÉ, Información privilegiada, Expansión, 29-III-2000, p. 62.
}

REVISTA DO DIREITO UNISC, SANTA CRUZ DO SUL No $41 \mid$ p. 110 - 168| NOV - DEZ 2013 
no sirve para crear nada, antes al contrario, lleva a las gentes a desconfiar de los poderosos y a realizar inversiones defensivas para cubrirse de sus abusos.

También hoy está de moda la malversación de fondos públicos. Se trata como es sabido, de que el funcionario público de a los caudales o efectos que administrare un uso ilícito. La malversación admite distintas modalidades: sustracción por acción u omisión o por omisión culposa, aplicación a usos privados o ajenos, aplicación pública diferente de la asignada o retención indebida de cosas. En sentido estricto, se trata de dar a los caudales públicos un destino público pero distinto a aquel a que estuvieran destinados. En estos supuestos, es claro que se produce una desnaturalización de las potestades públicas. 
La expresión "conflicto de intereses" no es ajena al mundo de la Administración pública ${ }^{86}$. Por ejemplo, en los Estados Unidos se ha ido mucho más lejos que en Francia al establecer una serie de estrictas obligaciones para los funcionarios. Así, la exigencia de hacer pública la situación financiera de los funcionarios norteamericanos será impensable en Francia donde existe, forma parte de la cultura burocrática, una fuerte conciencia de la privacidad del funcionario. En el país vecino, como nos comenta el profesor ROHR, se confía más en la tradición: en la idea de la función pública como una tarea de suma nobleza y, como consecuencia, en el Ilamado "espirit de corps". En Francia existen restricciones muy severas que dificultan que un funcionario pueda desempeñar un trabajo en el sector privado en el que pueda "aprovechar" los conocimientos o relaciones adquiridos durante el ejercicio de la función pública. En los Estados Unidos, sin embargo, las restricciones son más concretas y se limitan únicamente a las áreas que tienen una relación directa con el cargo público. En Francia, como dice ROHR, estas disposiciones prácticamente no se cumplen, mientras que en los Estados Unidos parece que si tienen una mayor aplicación real.

Es bien sabido que la cuestión del empleo posterior al desempeño de un cargo público está directamente relacionada con el llamado conflicto de interés ${ }^{87}$. En Canadá, por ejemplo, el llamado Libro Verde del Conflicto de Intereses de 1973 y los Proyectos de Ley a que dieron lugar, establecieron que lo esencial de la regulación de los conflictos de interés no reside tanto en la limitación impuesta a trabajos posteriores al desempeño del cargo público como a la prohibición de conflictos presentes entre las obligaciones de la función pública y sus intereses privados. Es decir, estos conflictos de interés se produce siempre que un cargo público o su cónyuge o "dependientes" tengan

\footnotetext{
${ }^{86}$ Sobre el tema, vid. P.E. BIGELOW, From norms to be rules: regulating the outside interests of public officials, en F. MAURO/G. BENJAMIN, Restructuring the New York city government, New York, 1989, pp. 201 y ss; R.N. ROBERTS-M.T. DOSS, Public service and private hospitality: a case study in federal conflict of interest reform, Public Administration Review, vol. 52, no 3, pp. 206 y ss. En España, vid. A. IZQUIERDO, Ética y Administración, cit, pp. 27 y ss.

${ }^{87}$ Vid. K.M. GIBBONS, The reform of lobbying in Cabada: Timid first step or bold new direction ?, Corruption and Reform, cit, pp. 205 y ss. y A. STARK, Public sector conflict of interest at the federal level in Canada and the US: differences in understanding and approach, Public Administration Review, vol. 52, no 5, 1992, pp. 477 y ss. En España, está a punto de publicarse la tesis doctoral de P. GARCÍA MEXÍA sobre este tema.
} 
importantes intereses privados que le proporcionen la posibilidad de beneficiarse, directa $o$ indirectamente, como consecuencia de sus acciones $u$ omisiones con ocasión del oficio público. En realidad, el conflicto de intereses es también otra variante de corrupción pues se trata, sobre todo, de beneficiarse personalmente del ejercicio de determinada función pública, bien sea durante el desempeño de la tarea pública o con posterioridad ${ }^{88}$.

El fraude fiscal es otra modalidad de corrupción bien grave pues altera significativamente la distribución de la renta y de la riqueza traicionando el principio de equidad, y forzando en ocasiones a que se incrementen la presión fiscal sobre los contribuyentes honestos ${ }^{89}$.

Quizás el gran problema de la corrupción sea el de la financiación de los partidos políticos. Como ha señalado atinadamente GARCíA AÑOVEROS, los partidos luchan por el poder y la tentación de buscar más dinero para competir con más garantías de éxito no es fácilmente vencible. Por eso, en los últimos años se ha organizado un sistema de financiación ilegal, bien participando en empresas que reparten beneficios únicamente por contar con el apoyo oficial, bien por exigir "donaciones", escribe el profesor SOTELO, disfrazadas de servicios, que no son más que el precio por mantener una cierta benevolencia con la empresa en cuestión. En estos años, es cierto que estas prácticas han aumentado hasta el punto de que no pocas veces, en lugar de llegar a su destino esas "donaciones", se pierden en la maraña de unas redes de intermediarios cada vez más numerosa. El tema es muy grave, no sólo porque muchas veces está en el origen de prevaricaciones, cohechos, malversaciones $u$ otras prácticas corruptas, sino porque si los partidos se

\footnotetext{
${ }^{88}$ Recientemente, una sentencia del Tribunal Supremo español, de 7.II.1995, condenó a un alcalde por fraude, de acuerdo con el artículo 401 del Código Penal por adjudicar obras municipales a la empresa de la que era administrador.

${ }^{89}$ Vid. sobre el tema, el $\mathrm{n}^{\circ} 6$ de 1994 de Cuadernos de Actualidad editado por el Instituto de Estudios Fiscales en el que hay un interesante informe de la Unidad Especial para el Estudio del Fraude y un estudio sobre el Plan de lucha contra el fraude que realiza la Agencia Tributaria. Vid. También el libro de M. MAGADÁN y el no 10 de la Revista Auditoría Pública dedicado monográficamente al fraude.
} 
financian con el ejercicio torcido e impropio de las potestades públicas, se "legitima" de algún modo, señala SOTELO, la misma corrupción ${ }^{90}$.

\section{G.- EFECTOS}

El efecto más perverso de la corrupción es probablemente el falseamiento del mismo sistema democrático y la consolidación de una forma de vida más bien alejada de los hábitos y virtudes propias de una democracia. Y si se trata de corrupción institucionalizada, la "doble" moral y la esquizofrenia se instala en una sociedad a la que sólo tiene acceso el poder, el dinero o la notoriedad.

Sin embargo, a efectos sistemáticos, se pueden señalar varias consecuencias de la corrupción que, por su interés, sobre todo para analizar la situación actual, vamos brevemente, a enumerar:

1․-- $\quad$ Se produce una quiebra muy grave en la función pública, que ya no se orienta a promover un clima de desarrollo de la persona y de sus derechos fundamentales.

2.- $\quad$ Se produce una evidente pérdida de categoría y calidad humana en quienes ocupan o desempeñan cargos públicos con la consiguiente y progresiva separación de ciudadanos y gobernantes.

$3^{\circ}$.- $\quad$ Se pierde profesionalidad en la tarea pública y se contagia una determinada forma de hacer o de "trabajar" opuesta a los valores propios del trabajo honesto.

$4^{\circ}$-- $\quad$ Se produce, igualmente, un falseamiento del sistema de mercado, se socavan los principios de publicidad y de concurrencia y, también, del de acceso a la función pública de acuerdo con el mérito y la capacidad.

\footnotetext{
${ }^{90}$ Vid. J. GARCÍA AÑOVEROS, Corrupción, clientelismo y transparencia, El País, 29.VI.1993, p. 5; I. SOTELO, Salirse por la tangente, El País, 21.IV.1993, p. 15; R. BLANCO VALDÉS, La financiación de los partidos políticos, Claves de la razón práctica, 1995, pp. 36 y ss, Tema para un debate: la financiación de los partidos políticos, Anuario del derecho Constitucional y Parlamentario, $\mathrm{n}^{\circ}$ 5, 1993, pp. 105 y ss; B. MALIGNER, E.DERIEVY, H.M.CRUCIS, Le loi du 29 janvier 1993 relative à la prèvention de la corruption et a la transparence de la vie economique et des procedures publiques, Revue Francaise de Droit Administratif, $\mathrm{n}^{\circ}$ 6, Nov-Dic 1993, pp. 1070 y ss y La Financiación de los partidos políticos, $\mathrm{n}^{\mathrm{o}} 47$ de Cuadernos y Debates del centro de Estudios Constitucionales, 1994, pp. 9 y ss.
} 
50.- $\quad$ Desde el punto de vista económico, se incrementan los costes de las empresas que acuden a las prácticas corruptas, lo que lleva a elevar el precio de los bienes y servicios que producen. $\mathrm{Y}$, cuando el demandante de esos bienes es la propia Administración pública, lógicamente, aumenta el gasto público. Y, si estas operaciones, como señala el profesor NIETO DE ALBA, se llevan a cabo a través de empresas que realizan la intermediación en el ámbito de la denominada economía sumergida, entonces las arcas públicas ven reducidos sus ingresos en la cuantía en que se evaden los impuestos. Es decir, incremento del déficit público.

6ํ.- $\quad$ Como es lógico, la corrupción produce una falta de racionalización en el gasto público, tanto en su eficiencia como en su eficacia.

$7^{7}$.- $\quad$ También, desde el punto de vista de los fondos públicos, se produce una clara relajación de los sistemas de control del gasto a través de fiscalizaciones "a posteriori", que ya nada pueden hacer más que constatar los desaguisados o escándalos.

8‥- Otro efecto, no menos grave, es que la corrupción, desgraciadamente, aleja de las tarea públicas a aquellas personas que podrían prestar un servicio al bien común con su participación en la dirección de la cosa pública. Y, por el contrario, fomenta la partitocracia, las comisiones ilegales a los partidos políticos y, en definitiva, un clima social de engaño y mentira en el que todo se mide en función del dinero y del poder, y en el que se pierde, poco a poco, la referencia humana que, tan importante es, y que, a pesar de los pesares, es la referencia fundamental del sistema democrático. 